\title{
Immature Instars of Three Species of Rhodnius (Hemiptera, Reduviidae, Triatominae): Morphological and Morphometric Studies
}

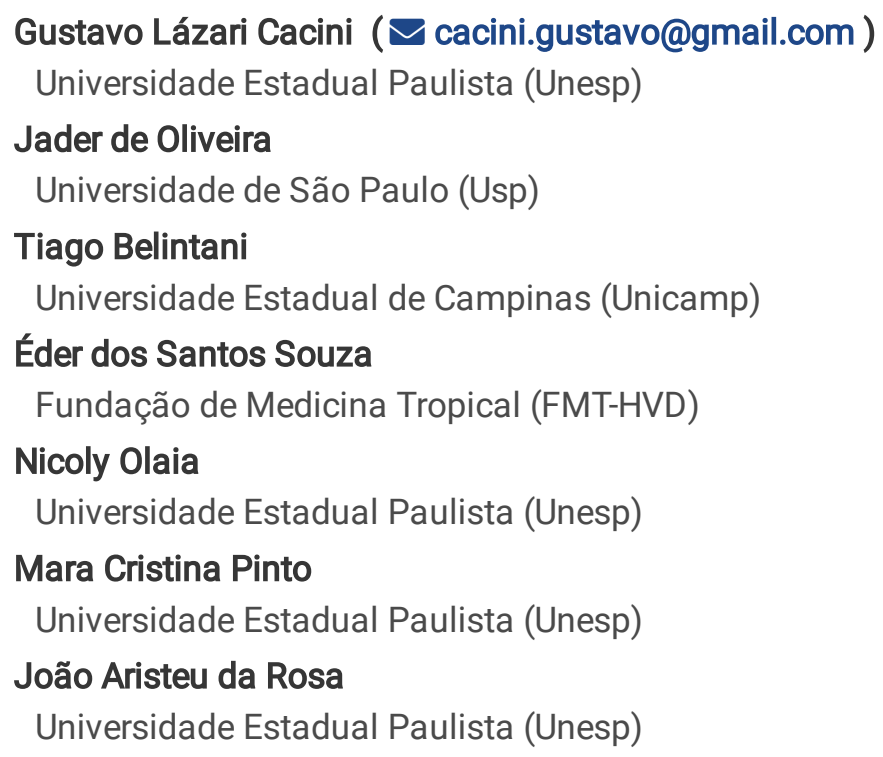

Research

Keywords: Chagas Disease, Vector, Rhodniini, Triatomines, Rhodnius.

Posted Date: November 11th, 2021

DOI: https://doi.org/10.21203/rs.3.rs-1048344/v1

License: () (1) This work is licensed under a Creative Commons Attribution 4.0 International License. Read Full License 


\section{Abstract}

Background: Among the 18 genera of the Triatominae subfamily, three stand out for their diversity and epidemiological importance: Triatoma, Panstrongylus, and Rhodnius. The genus Rhodnius includes 21 species that can transmit Trypanosoma cruzi (the etiological agent of Chagas disease, also known as American trypanosomiasis) and Trypanosoma rangeli. The Rhodnius prolixus complex comprises seven species, including Rhodnius marabaensis, Rhodnius prolixus, and Rhodnius robustus, which occur in Northern region of Brazil. Since both adults and immatures can carry T. cruzi, in this study the five nymphal instars of the three species mentioned were dorsally characterized.

Methods: By means of light microscopy, morphometrics and geometric morphometrics, the present work measures and describes the morphological characters of the five nymphal instars of Rhodnius marabaensis, Rhodnius prolixus, and Rhodnius robustus.

Results: The study allowed the characterization of all the five nymphal instars, as well as the distinction between the three species in each of their instars.

Conclusions: The morphological, morphometrics of the head, thorax, and abdomen and geometric morphometrics studies of the head enabled the specific distinction of these three species in all the five instars.

\section{Background}

Chagas disease is an endemic infection in the Americas caused by the protozoan Trypanosoma cruzi (Chagas 1909) [1] and transmitted mainly by triatomines [2]. In South America, the Amazon region has a large potential to disseminate the disease, both for the relevant number of triatomine species living there and the difficulties related to vector surveillance and control [3]. In addition to the transmission by faecal contamination after the bite, cases by oral transmission occur due to the ingestion of food contaminated with T. cruzi, such as açaí (Euterpe oleracea Mart. 1824) juice, bacaba (Oenocarpus bacaba Mart 1823) juice, jaci (Attalea butyracea (Mutis ex L.f.) Wess.Boer) juice, orange (Citrus sinensis L. Osbeck, var. Pera-Rio) juice, guava (Psidium guajava Linnaeus 1753) juice, sugarcane juice, and palm wine [3, 4, 5].

All species of Triatominae are potential vectors and can transmit T. cruzi $[6,7,8]$. These species are placed into 18 genera, including Rhodnius Stål, 1859, which in addition to T. cruzi can transmit Trypanosoma rangeli Tejera, 1920 [9]. This genus has 21 species [10], of which 10 are found in Northern Brazil: Rhodnius amazonicus Almeida, Santos \& Sposina, 1973; Rhodnius barretti Abad-Franch et al., 2013; Rhodnius brethesi Matta, 1919; Rhodnius milesi Carcavallo et al., 2001; Rhodnius montenegrensis Rosa et al., 2012; Rhodnius paraensis Sherlock et al., 1977; Rhodnius pictipes Stål, 1872; Rhodnius prolixus Stål, 1859; Rhodnius robustus Larrousse, 1927; and Rhodnius marabaensis Souza et al., 2016 [11, 12].

Species in this genus present well defined morphological characters that facilitate their identification in the Triatominae subfamily but distinguishing them from one another is a complex task [2,13]. The typical morphology of Rhodnius is characterized by the position of the antennal tubercle on the apex of the head and the absence of phallosome support in the genitalia of some species $[2,11,13]$. Their colour tends towards dark/light brown, with spots that can be sharp [2]. Nymphs are characterized by an elongated head, antennal tubercles located in the anterior one-third or one-fourth of the anteocular area, no ocelli, spotted abdomen on the back, without the row of median tubercles $[2,9,13,14,15]$. Because of the related taxonomic difficulties and its epidemiological importance, the genus is widely studied, yet its phylogeny has not been clarified and requires new studies $[10,16]$.

The tribe Rhodniini (Rhodnius + Psamolestes Bergroth, 1911) consists of a monophyletic group of two genera naturally occurring in the Neotropical region [17]. Arboreal habits are common in the genus, and most of them are associated with one or more palm species. Among the species studied in this work, Rhodnius robustus is found in Bolivia, Colombia, Ecuador, Peru, Venezuela, as well as Northern Brazil $[2,18]$. In wild environments it is generally found in a variety of palm species, its presence having also been reported in domiciles and peridomiciles $[19,20]$. This species is also related to food contamination 
and infection of forestry workers [21, 22]. Rhodnius robustus is very close to $R$. montenegrensis, but molecular studies have confirmed the specific status of each species $[23,24]$.

Rhodnius marabaensis, which was described in 2016, was collected in the state of Pará. It has a straw colour, and its dorsal thorax has a trapezoidal shape limited by a straw carina. Its lobes usually show a black-spot pattern. The larger length of the second antennal segment and the keel-shaped head apex are two of the main phenotypic features of adults [11]. Recently, Rhodnius marabaensis had its specific status validated by transposable element analysis [24], as well as its biological cycle [25]. It is a species found in the wild with moderate epidemiological importance [11].

Rhodnius prolixus is considered the most important species in the transmission of Chagas disease in Venezuela, Colombia, and Central America $[2,18]$. One of the factors that contribute to this is that the species is optimally adapted to human dwellings. This triatomine is similar to $R$. robustus, which makes the specific diagnosis more difficult [26].

Taking all these considerations into account, this study aims to characterize $R$. marabaensis, $R$. prolixus, and $R$. robustus both morphologically and morphometrically, making it easier to distinguish these three species in the five nymphal instars. Although the epidemiological importance of $R$. marabaensis is still unknown on account of its recent description, $R$. prolixus and $R$. robustus are important vectors of Chagas disease in the areas where they occur.

\section{Methods}

\section{Specimens}

Specimens maintained in the Triatominae Insectarium at the Faculty of Pharmaceutical Sciences of the São Paulo State University (Unesp-Araraquara) (https://www2.fcfar.unesp.br/\#!/triatominae/) were used. Rhodnius marabaensis specimens (Figures 1-5A-B) that originated the colony were collected in the county of Marabá, state of Pará, Brazil. The founders of the R. prolixus colony (Figures 1-5C-D) came from Venezuela. Rhodnius robustus specimens (Figures 1-5E-F) that originated the colony were collected in the county of Ouro Preto do Oeste, state of Rondônia, Brazil. Nymphs of 1st, 2nd, 3rd, 4th, and 5th instars were taken from the respective colonies on the day they were utilized. First instar nymphs were selected after egg hatching without being fed. Nymphs of 2nd, 3rd, 4th, and 5th instars were selected immediately after ecdysis. The morphological and morphometric studies were conducted without verifying the gender distinction of the five nymphal instars. All nymphs were fed every seven days and later were frozen for subsequent image generation.

\section{Morphological study}

To generate images, five specimens of each of the five instars of $R$. marabaensis, $R$. prolixus, and $R$. robustus were used. Images of the dorsal sides of head, thorax, and abdomen as well as the complete images of each of the five instars from dorsal and ventral view were obtained using a Leica M205 stereoscopic microscope and the Leica Application Suite X software.

\section{Morphometric study}

Fifteen specimens of 1st, 2nd, 3rd, 4th, and 5th instar nymphs of $R$. marabaensis, $R$. prolixus, and $R$. robustus were measured using a Leica MZ APO stereoscopic microscope and the Motic Advanced 3.2 plus image analysis system.

Nymphs of all instars had their total length $(T L)$, head length $(H L)$, thorax length $(X L)$ and abdomen length (AL) measured. Following Dujardin et al. [27], interocular (IO), anteocular (AO) and postocular (PO) distances were measured, as well as the three segments of the proboscis. The four antennal segments were also measured, according to Rosa et al. [28]. The length of all the parameters was measured in millimeters.

The obtained data were analyzed by descriptive statistics, using t-test for mean, standard deviation. An ANOVA and Tukey's pairwise to evaluate the degree of differentiation of the three species using the Past software.

Page 3/26 


\section{Geometric morphometrics of heads}

Geometric morphometrics was used to evaluate variations in head shape and size using Cartesian reference coordinates. Variations among the heads of all nymphal instars of the studied species were evaluated. Fifteen heads of each instar were selected, and the images were obtained by means of a stereoscopic magnifying glass coupled to the Motic Advanced 3.2 plus scanning system. The coordinates of the reference points were selected according to Bookstein [29]. Ten anatomical landmarks of Type 1 (for example, intersection between veins) were collected and processed using the modules available in the tps Dig v.1.18 software [30]. Four anatomical landmarks were digitized for the 1 st instar of development and five anatomical landmarks were selected for the other instars of development; the landmarks being digitized using the CLIC package (https://xyom-clic.eu/the-clic-package/). Then the file with the raw coordinates was used for a generalized Procrustes analysis (GPA). GPA is a method that allows eliminating all the information related to size, position, and orientation of previously digitized anatomical frames [30]. The matrix of form was held in a Euclidean space to generate a set of marks known as partial warps [29]. All the additional statistical forms were performed using Procrustes residues to analyze differences in the size and shape of the heads of each nymphal instar. Procrustes ANOVA $(p<0.0001)$ [31] is used to infer differences between species. Procrustes ANOVA is a method for quantifying relative amounts of variation at different levels. These differences in size were assessed using an isometric estimator de-fined as centroid size (CS) [32]. Mahalanobis distances between pairs of species were calculated for measurements of shape and significance was assessed using a nonparametric test based on permutations (bootstrap, 10000 replications) using MorphoJ [33]. In addition to that, using distance dice from Mahalanobis, neighbor-joining trees (NJ) were recovered using PAST v.3.25 [34]. To determine the relationships between species, canonical variable analysis (CVA) was performed using MorphoJ [33]. The CVA was performed associated with a resampling method (bootstrap, 10000 replications) to build regions of trust in relation to the median size of the species centre. A factorial map of the first two canonical fathers was created using MorphoJ, version 1.0.7a [33].

\section{Results}

\section{Morphological description of the five nymphal instars of R. marabaensis, R. prolixus, and R. robustus by optical microscopy}

First instar: the head of the nymphs has a dark-brown cuticle covering all its granular extension due to the presence of tubercles with small sensilla, whose colour is darker than that of the cuticle. Gena and juga showed no significant differences among the species. Regarding the postocular area, the species shows Y-shaped cephalic sutures (Figure 6A-C). On the thorax there are tubercles with sensilla in the three segments, located mainly in the centre. The prothorax has a trapezoidal shape and is the segment with larger external borders, followed by the metathorax and the mesothorax. The three segments are well delimited by the dividing lines, but the line separating the mesothorax from the metathorax shows a sinuous protuberance that overlaps the metathorax in about one-third of its size. The metathorax is broad on the sides and narrow in the central portion (Figure 6D-F), while, near segment I of the abdomen of $R$. robustus, there is a marked convexity that is not seen in $R$. marabaensis and $R$. prolixus. The abdomen of 1 st instar nymphs has a lighter colour in comparison with the thorax and the head. There are many tubercles with sensilla lighter-coloured than the cuticle. A lighter median longitudinal strip can be seen all over the abdomen. Darker spots are noticed along the connexivum (Figure 6G-I). The abdomen of the three species is different in shape: $R$. prolixus has a larger abdomen than $R$. marabaensis and $R$. robustus, particularly between segments III and VI. The abdomen of $R$. robustus widens gradually from segment I to IV, which is broader, then it starts to narrow, also gradually. In $R$. marabaensis segments IV and $\mathrm{V}$ are the broadest of the abdomen. In $R$. marabaensis and $R$. prolixus segment I of the abdomen has the same length as the metanotum, whereas in $R$. robustus it is longer than the metanotum (Figure 6GI).

Second instar: the general aspects of the head of 2 nd instar nymphs follow the pattern described for 1 st instar nymphs. However, some differences are noticeable, such as the increase in the granulation grade and the number of sensilla in the three species, as well as the lighter colour of the cuticle (Figure 7A-C). Tubercles with sensilla are present in the three segments of the thorax, located mainly in the central portion. The prothorax has the form of a trapezium and is the segment with the largest external borders, and it is longer in $R$. prolixus than in $R$. marabaensis and $R$. robustus. It is not possible to 
identify the difference in size between the mesothorax and the metathorax, but, as in the 1st instar, the metathorax is broad on the sides and narrow in the central portion. The three segments are well delimited by the dividing lines, but the line separating the mesothorax from the metathorax has a sinuous protuberance that overlaps the metathorax in about one-third of its size. At the central limit between the mesonotum and the metanotum, the dividing line is straight in $R$. marabaensis and $R$. robustus, whereas in $R$. prolixus it is concave (Figure 7D-F). The abdomen has a median spot lighter than the cuticle in the dividing line of each of the urotergites, resembling a strip. The connexivum spots become more evident in this instar. The abdomen of $R$. prolixus has the maximum width in segment $\mathrm{V}$. The external limits of the abdomen of $R$. marabaensis between segments III and VI are straight. The abdomen of $R$. robustus is like the 1 st instar, i.e., it widens gradually from segment I to IV and from this segment on it narrows gradually (Figure 7G-I).

Third instar: for the three species, in the third instar gena are more rounded and extend until the end of the clypeus. Postocular cephalic sutures are also more rounded and roughly have a U-shape (Figure 8A-C). From dorsal view the head of $R$. marabaensis shows a prominent white strip that starts at the antennal tubercle and extends until the neck (Figure 8A). In $R$. prolixus this strip is not so evident, and in $R$. robustus it is visible between the clypeus and the antennal tubercles; posteriorly it is visible in the intermediate portion and between the posterior region of the eye and the neck (Figure 8B-C). Tubercles with sensilla are present in the three segments of the thorax, distributed across them. The prothorax has the shape of a trapezium and is the segment with the largest external borders, followed by the mesothorax and the metathorax. The three segments are well delimited by the dividing lines, but the line separating the mesothorax from the metathorax has a sinuous protuberance that overlaps the metathorax in about one third of its size. The mesonotum of $R$. prolixus shows a concavity in the central portion, near the metanotum, whereas this concavity is not seen in $R$. marabaensis and $R$. robustus (Figure 8D-F). The three species possesses $2+2$ dark strips across the abdomen. An increase of spots in the connexivum can also be observed. In $R$. marabaensis abdominal segments III and IV are the broadest. The segments widen from segment I to III and gradually narrow from segment VI onwards. A central strip of straw colour is also easily visible on the abdomen of this species, and from the sides there is another straw strip, located between two black strips. These three strips are arched and have the same shape as the abdomen, but they are not continuous, as they are interrupted in the intersegmental sutures. In $R$. prolixus and $R$. robustus the largest abdominal segment is the IV. The central strip that travels across the abdomen also distinguishes the three species in this instar: in $R$. marabaensis this strip has straw-colored marks elongated in each segment; in $R$. prolixus such marks are neither so elongated nor clear, whereas in $R$. robustus they are not elongated, yet clear (Figure 8G-I).

Fourth instar: 4th instar nymphs present some peculiar characteristics, such as triangular juga, rounded gena surpassing the clypeus, and a higher granulation grade near the eyes. As in the third instar, the white strip on the head is very clear in $R$. marabaensis. The strip is present in $R$. prolixus, but it is narrower, and in $R$. robustus it is less clear in the intermediate portion (Figure 9A-C). The three segments of the thorax have tubercles with sensilla. The mesothorax is the largest segment in this instar due to the presence of the first pair of wing pads. The second pair of wing pads originates from the metathorax. The three segments are well delimited by the dividing lines. The line separating the prothorax from the mesothorax has a slight sinuosity overlapping a tiny part of the mesothorax in $R$. marabaensis and $R$. prolixus. In $R$. robustus the line separating the mesothorax from the metathorax has a concave aspect, the same for the line between the metathorax and the beginning of the abdomen (Figure 9D-F). In all three species the dark strips on the abdomen are more evident, which gives the area a striped aspect. In this instar the connexivum spots become more rounded. The central strip on the abdomen has the same aspect as in the 3rd instar and differentiates the three species: in $R$. marabaensis the three side strips on the abdomen, a straw strip between two black ones to the right and left, are similar to what is observed in the 3rd instar (Figure 9G-I).

Fifth instar: in this instar all three species also have a quite visible white strip on the head. The gena of $R$. marabaensis reach the initial limit of the clypeus, which is straight; the anteclypeus is curve (Figure 10A). In $R$. prolixus the gena surpass the clypeus, which is curve at the beginning, and the anteclypeus has a trapezoidal shape (Figure 10B). The gena of $R$. robustus reach the limit of the clypeus, which initially has a concave form, whereas the anteclypeus has a semicircular shape (Figure 10C). There are tubercles with sensilla in the three segments of the thorax. The posterior pair of wing pads can be seen overlapping, projecting from the mesonotum through the anterior pair, which in turn projects from the mesothorax (Figure 10D-F). It is possible to see only the central area of the metathorax as a result of this large overlapping. The anterior pair of 
wing pads reach the beginning of the 3rd urotergite. The side limit of the anterior wing pads is determined by a clear line in $R$. prolixus and $R$. robustus, while in $R$. marabaensis the line is broad and diffuse (Figure 10D-F). The abdomen of $R$. prolixus and $R$. robustus is more elongated than that of $R$. marabaensis. In this instar the central line of the abdomen retains the characteristics observed in the 3rd and 4th instars. In $R$. marabaensis the three side strips on the right and left (one straw and two black) noticed in the 3rd and 4th instars are still present. There is also an increase in the number of tubercles with sensilla (Figure 10G-I).

Morphometric study of the five nymphal instars of R. marabaensis, R. prolixus, and R. robustus

With the acquired data it was possible to calculate the mean for each parameter and species, and then compare them to evaluate the degree in which the three Rhodnius species differ.

In the first and second instars, none of the parameters were statistically significant to evaluate the degree of the differences among the three Rhodnius species. As for the third instar, the parameter of the 3rd segment of the antenna $\left(F_{(2,42)} 23.12, p=\right.$ 1.693) was significant (Table 1). The 4 th instar only the postocular distance stands out $\left(F_{(2,42)} 13.64, p=2.718\right)($ Table 2$)$. Lastly, on the 5 th instar just the 2 nd segment of the antenna $\left(F_{(2,42)} 36.32, p=6.965\right)$ (Table 1$)$ made it possible to evaluate the degree of the difference between $R$. marabaensis, $R$. prolixus and $R$. robustus. ${ }^{\star \star *}$ Insert tables here ${ }^{\star *}$ 
Table 1

- Mean and standard deviation of the antennal and proboscis segments of three species of Rhodnius.

\begin{tabular}{|c|c|c|c|c|c|c|c|c|}
\hline \multirow[t]{3}{*}{ Instars } & \multirow[t]{3}{*}{ Species } & \multicolumn{7}{|l|}{ Characters } \\
\hline & & \multicolumn{4}{|l|}{ Antenna } & \multicolumn{3}{|l|}{ Proboscis } \\
\hline & & 1st seg & 2nd seg & 3rd seg & 4th seg & 1st seg & 2nd seg & 3rd seg \\
\hline & $R$ & $0.14 \pm 0.02$ & $0.36 \pm 0.02$ & $0.69 \pm 0.03$ & $0.64 \pm 0.03$ & $0.17 \pm 0.01$ & $0.52 \pm 0.02$ & $0.29 \pm 0.01$ \\
\hline & marabaensis & A & A & A & A & A & A & \\
\hline \multirow[t]{3}{*}{$1 \mathrm{st}$} & R. prolixus & $\begin{array}{l}0.13 \pm 0.01 \\
A\end{array}$ & $\begin{array}{l}0.43 \pm 0.02 \\
B\end{array}$ & $\begin{array}{l}0.73 \pm 0.03 \\
B\end{array}$ & $\begin{array}{l}0.62 \pm 0.03 \\
A\end{array}$ & $\begin{array}{l}0.17 \pm 0.01 \\
A B\end{array}$ & $\begin{array}{l}0.54 \pm 0.02 \\
B C\end{array}$ & $\begin{array}{l}0.28 \pm 0.01 \\
\text { AC }\end{array}$ \\
\hline & R. robustus & $\begin{array}{l}0.13 \pm 0.01 \\
A\end{array}$ & $\begin{array}{l}0.37 \pm 0.02 \\
A\end{array}$ & $\begin{array}{l}0.68 \pm 0.03 \\
A\end{array}$ & $\begin{array}{l}0.63 \pm 0.05 \\
A\end{array}$ & $\begin{array}{l}0.16 \pm 0.01 \\
A C\end{array}$ & $\begin{array}{l}0.53 \pm 0.03 \\
\text { AC }\end{array}$ & $\begin{array}{l}0.27 \pm 0.03 \\
\mathrm{BC}\end{array}$ \\
\hline & $\begin{array}{l}R . \\
\text { marabaensis }\end{array}$ & $\begin{array}{l}0.17 \pm 0.01 \\
A\end{array}$ & $\begin{array}{l}0.60 \pm 0.03 \\
A\end{array}$ & $\begin{array}{l}0.94 \pm 0.03 \\
\text { A }\end{array}$ & $\begin{array}{l}0.83 \pm 0.06 \\
\mathrm{~A}\end{array}$ & $\begin{array}{l}0.24 \pm 0.02 \\
\text { A }\end{array}$ & $\begin{array}{l}0.86 \pm 0.03 \\
A\end{array}$ & $\begin{array}{l}0.34 \pm 0.01 \\
\text { A }\end{array}$ \\
\hline \multirow[t]{3}{*}{$2 n d$} & R. prolixus & $\begin{array}{l}0.17 \pm 0.01 \\
A B\end{array}$ & $\begin{array}{l}0.68 \pm 0.03 \\
B\end{array}$ & $\begin{array}{l}0.95 \pm 0.05 \\
A\end{array}$ & $\begin{array}{l}0.78 \pm 0.05 \\
A\end{array}$ & $\begin{array}{l}0.26 \pm 0.01 \\
B\end{array}$ & $\begin{array}{l}0.86 \pm 0.02 \\
A\end{array}$ & $\begin{array}{l}0.37 \pm 0.01 \\
\text { B }\end{array}$ \\
\hline & R. robustus & $\begin{array}{l}0.16 \pm 0.01 \\
A C\end{array}$ & $\begin{array}{l}0.59 \pm 0.04 \\
A\end{array}$ & $\begin{array}{l}0.93 \pm 0.05 \\
A\end{array}$ & $\begin{array}{l}0.79 \pm 0.05 \\
A\end{array}$ & $\begin{array}{l}0.24 \pm 0.01 \\
A\end{array}$ & $\begin{array}{l}0.81 \pm 0.04 \\
B\end{array}$ & $\begin{array}{l}0.35 \pm 0.02 \\
A\end{array}$ \\
\hline & & $0.22 \pm 0.01$ & $0.99 \pm 0.05$ & $1.29 \pm 0.05$ & $1.05 \pm 0.08$ & $0.38 \pm 0.03$ & $1.25 \pm 0.08$ & $0.43 \pm 0.02$ \\
\hline \multirow[t]{3}{*}{$3 r d$} & R. prolixus & $\begin{array}{l}0.22 \pm 0.01 \\
A\end{array}$ & $\begin{array}{l}0.94 \pm 0.03 \\
B\end{array}$ & $\begin{array}{l}1.16 \pm 0.05 \\
B\end{array}$ & $\begin{array}{l}0.88 \pm 0.08 \\
B\end{array}$ & $\begin{array}{l}0.35 \pm 0.03 \\
B\end{array}$ & $\begin{array}{l}1.21 \pm 0.07 \\
A B\end{array}$ & $\begin{array}{l}0.45 \pm 0.02 \\
A\end{array}$ \\
\hline & R. robustus & $\begin{array}{l}0.22 \pm 0.01 \\
A\end{array}$ & $\begin{array}{l}0.99 \pm 0.03 \\
A\end{array}$ & $\begin{array}{l}1.24 \pm 0.05 \\
c\end{array}$ & $\begin{array}{l}0.95 \pm 0.10 \\
B\end{array}$ & $\begin{array}{l}0.39 \pm 0.01 \\
A\end{array}$ & $\begin{array}{l}1.29 \pm 0.10 \\
A C\end{array}$ & $\begin{array}{l}0.44 \pm 0.03 \\
\text { A }\end{array}$ \\
\hline & $\begin{array}{l}R \text {. } \\
\text { marabaensis }\end{array}$ & $\begin{array}{l}0.30 \pm 0.01 \\
A\end{array}$ & $1.64 \pm 0.15$ & $\begin{array}{l}1.73 \pm 0.14 \\
A\end{array}$ & $\begin{array}{l}1.38 \pm 0.16 \\
A\end{array}$ & $\begin{array}{l}0.55 \pm 0.04 \\
A\end{array}$ & $\begin{array}{l}2.17 \pm 0.15 \\
\text { A }\end{array}$ & $\begin{array}{l}0.63 \pm 0.05 \\
A\end{array}$ \\
\hline \multirow[t]{3}{*}{ 4th } & R. prolixus & $\begin{array}{l}0.29 \pm 0.02 \\
A\end{array}$ & $\begin{array}{l}1.39 \pm 0.09 \\
B\end{array}$ & $\begin{array}{l}1.46 \pm 0.13 \\
B\end{array}$ & $\begin{array}{l}1.12 \pm 0.08 \\
B\end{array}$ & $\begin{array}{l}0.58 \pm 0.07 \\
A B\end{array}$ & $\begin{array}{l}1.95 \pm 0.07 \\
B\end{array}$ & $\begin{array}{l}0.64 \pm 0.05 \\
\text { A }\end{array}$ \\
\hline & R. robustus & $\begin{array}{l}0.32 \pm 0.01 \\
B\end{array}$ & $\begin{array}{l}1.65 \pm 0.10 \\
A\end{array}$ & $\begin{array}{l}1.67 \pm 0.10 \\
\text { A }\end{array}$ & $\begin{array}{l}1.31 \pm 0.09 \\
\text { A }\end{array}$ & $\begin{array}{l}0.52 \pm 0.06 \\
\text { AC }\end{array}$ & $\begin{array}{l}1.87 \pm 0.08 \\
B\end{array}$ & $\begin{array}{l}0.54 \pm 0.06 \\
B\end{array}$ \\
\hline & R. & $0.41 \pm 0.02$ & $2.71 \pm 0.13$ & $2.36 \pm 0.09$ & $1.60 \pm 0.23$ & $0.73 \pm 0.05$ & $3.10 \pm 0.15$ & $0.79 \pm 0.04$ \\
\hline \multirow[t]{2}{*}{5 th } & R. prolixus & $\begin{array}{l}0.40 \pm 0.01 \\
A\end{array}$ & $\begin{array}{l}2.17 \pm 0.10 \\
B\end{array}$ & $\begin{array}{l}1.90 \pm 0.15 \\
B\end{array}$ & $\begin{array}{l}1.37 \pm 0.12 \\
B C\end{array}$ & $\begin{array}{l}0.74 \pm 0.05 \\
A C\end{array}$ & $\begin{array}{l}2.66 \pm 0.06 \\
B\end{array}$ & $\begin{array}{l}0.75 \pm 0.07 \\
A B\end{array}$ \\
\hline & R. robustus & $\begin{array}{l}0.40 \pm 0.02 \\
A\end{array}$ & $\begin{array}{l}2.48 \pm 0.24 \\
C\end{array}$ & $\begin{array}{l}2.19 \pm 0.29 \\
\text { A }\end{array}$ & $\begin{array}{l}1.47 \pm 0.21 \\
A C\end{array}$ & $\begin{array}{l}0.79 \pm 0.05 \\
B C\end{array}$ & $\begin{array}{l}3.15 \pm 0.15 \\
A\end{array}$ & $\begin{array}{l}0.83 \pm 0.03 \\
A C\end{array}$ \\
\hline & ifferent sı & ripts at & site are & ficantly & ent fron & ner (one- & ANOVA fo & $\begin{array}{l}\text { ved by a } \\
\text { 's }\end{array}$ \\
\hline
\end{tabular}


Table 2

- Mean and standard deviation of the parameters of the three species of Rhodnius.

\begin{tabular}{|c|c|c|c|c|c|c|c|c|}
\hline \multirow[t]{2}{*}{ Instars } & \multirow[t]{2}{*}{ Species } & \multicolumn{7}{|l|}{ Characters } \\
\hline & & TL & HL & $\mathrm{XL}$ & $\mathrm{AL}$ & 10 & AO & PO \\
\hline & $R$ & $2.55 \pm 0.08$ & $0.87 \pm 0.02$ & $0.38 \pm 0.01$ & $1.17 \pm 0.07$ & $0.30 \pm 0.01$ & $0.52 \pm 0.02$ & $0.22 \pm 0.02$ \\
\hline & marabaensis & A & A & A & A & A & A & A \\
\hline \multirow[t]{3}{*}{$1 \mathrm{st}$} & R. prolixus & $\begin{array}{l}2.66 \pm 0.14 \\
A B\end{array}$ & $\begin{array}{l}0.89 \pm 0.03 \\
A B\end{array}$ & $\begin{array}{l}0.37 \pm 0.02 \\
\text { A }\end{array}$ & $\begin{array}{l}1.29 \pm 0.10 \\
B\end{array}$ & $\begin{array}{l}0.29 \pm 0.02 \\
\text { A }\end{array}$ & $\begin{array}{l}0.55 \pm 0.03 \\
B\end{array}$ & $\begin{array}{l}0.21 \pm 0.01 \\
B\end{array}$ \\
\hline & R. robustus & $\begin{array}{l}2.51 \pm 0.15 \\
\text { AC }\end{array}$ & $\begin{array}{l}0.85 \pm 0.02 \\
A C\end{array}$ & $\begin{array}{l}0.56 \pm 0.02 \\
A\end{array}$ & $\begin{array}{l}1.09 \pm 0.11 \\
A\end{array}$ & $\begin{array}{l}0.29 \pm 0.03 \\
\text { A }\end{array}$ & $\begin{array}{l}0.49 \pm 0.03 \\
A\end{array}$ & $\begin{array}{l}0.23 \pm 0.02 \\
A\end{array}$ \\
\hline & $R$. & $4.49 \pm 0.38$ & $1.24 \pm 0.03$ & $0.65 \pm 0.03$ & $2.22 \pm 0.14$ & $0.36 \pm 0.01$ & $0.81 \pm 0.02$ & $0.26 \pm 0.02$ \\
\hline \multirow[t]{4}{*}{$2 n d$} & R. prolixus & $4.56 \pm 0.33$ & $1.27 \pm 0.04$ & $0.68 \pm 0.04$ & $2.42 \pm 0.19$ & $0.37 \pm 0.02$ & $0.83 \pm 0.03$ & $0.26 \pm 0.01$ \\
\hline & R. robustus & $4.22 \pm 0.36$ & $1.20 \pm 0.07$ & $0.63 \pm 0.05$ & $2.11 \pm 0.22$ & $0.34 \pm 0.02$ & $0.78 \pm 0.06$ & $0.25 \pm 0.02$ \\
\hline & & $6.53 \pm 0.30$ & $1.77 \pm 0.07$ & $0.96 \pm 0.05$ & $3.21 \pm 0.20$ & $0.43 \pm 0.03$ & $1.13 \pm 0.05$ & $0.37 \pm 0.02$ \\
\hline & marabaensis & & A & & & & & \\
\hline \multirow[t]{4}{*}{$3 r d$} & R. prolixus & $6.63 \pm 0.26$ & $1.62 \pm 0.05$ & $0.99 \pm 0.04$ & $3.45 \pm 0.34$ & $0.45 \pm 0.02$ & $1.16 \pm 0.03$ & $0.33 \pm 0.02$ \\
\hline & R. robustus & $6.84 \pm 0.39$ & $1.81 \pm 0.09$ & $1.02 \pm 0.06$ & $3.44 \pm 0.19$ & $0.46 \pm 0.02$ & $1.16 \pm 0.06$ & $0.33 \pm 0.02$ \\
\hline & & & & & & & & \\
\hline & $\begin{array}{l}R . \\
\text { marabaensis }\end{array}$ & $10.19 \pm 0.46$ & $\begin{array}{l}2.74 \pm 0.16 \\
A\end{array}$ & $1.78 \pm 0.12$ & $\begin{array}{l}5.13 \pm 0.34 \\
A\end{array}$ & $\begin{array}{l}0.63 \pm 0.03 \\
A\end{array}$ & $1.94 \pm 0.12$ & $\begin{array}{l}0.51 \pm 0.03 \\
A\end{array}$ \\
\hline \multirow[t]{5}{*}{ 4th } & R. prolixus & $10.51 \pm 0.40$ & $2.60 \pm 0.09$ & $1.78 \pm 0.08$ & $5.31 \pm 0.28$ & $0.65 \pm 0.02$ & $1.84 \pm 0.06$ & $0.47 \pm 0.02$ \\
\hline & & A & $\mathrm{BC}$ & A & A & & B & \\
\hline & R. robustus & $10.57 \pm 0.54$ & $\begin{array}{l}2.69 \pm 0.12 \\
A C\end{array}$ & $1.83 \pm 0.08$ & $5.31 \pm 0.44$ & $0.65 \pm 0.03$ & $1.93 \pm 0.08$ & $0.49 \pm 0.02$ \\
\hline & & $13.63 \pm 0.50$ & $3.88 \pm 0.19$ & $2.95 \pm 0.15$ & $7.34 \pm 0.40$ & $0.82 \pm 0.04$ & $2.72 \pm 0.12$ & $0.67 \pm 0.05$ \\
\hline & marabaensis & & A & A & A & & A & \\
\hline \multirow[t]{2}{*}{5 th } & R. prolixus & $\begin{array}{l}13.33 \pm 0.40 \\
A\end{array}$ & $\begin{array}{l}3.57 \pm 0.16 \\
B\end{array}$ & $\begin{array}{l}2.86 \pm 0.13 \\
A B\end{array}$ & $\begin{array}{l}7.31 \pm 0.39 \\
A\end{array}$ & $\begin{array}{l}0.82 \pm 0.03 \\
A C\end{array}$ & $2.48 \pm 0.11$ & $0.59 \pm 0.02$ \\
\hline & R. robustus & $13.39 \pm 0.70$ & $\begin{array}{l}3.94 \pm 0.19 \\
A\end{array}$ & $3.01 \pm 0.16$ & $7.39 \pm 0.49$ & $0.86 \pm 0.03$ & $2.73 \pm 0.14$ & $0.65 \pm 0.02$ \\
\hline Mea & lifferent sı & cripts at & site are & cantly d & from $\mathrm{e}$ & her (o & $\begin{array}{l}\text { ANOVA fo } \\
\text { isons in Tu} \\
\text { XL: thorax }\end{array}$ & $\begin{array}{l}\text { wed by a } \\
\text { 's } \\
\text { th; AL: }\end{array}$ \\
\hline
\end{tabular}

Geometric morphometrics of the five nymphal instars of R. marabaensis, R. prolixus, and R. robustus

By ontogenetic geometric morphometry of the heads of nymphs, it was possible to describe the differences in shape and size of the five instars of $R$. robustus, $R$. prolixus, and $R$. marabaensis. Centroid size (CS) measures show variability in head size of the species. Furthermore, by the isometric measurement of the centroid size, the size gain among immature shapes can be clearly seen (Figure 11). Analysis of centroid size shows that differences among the size means are significant $(p<0.0001$, 
supplementary material). Rhodnius robustus and R. prolixus have larger size means compared to R. marabaensis (Figure 11). Differences can also be explained as a percentage of the total variance among groups in the Eigenvalues (auto values), the percentages being: $89 \%$ for the 1 st instar, $83 \%$ for the 2 nd, $98 \%$ for the $3 \mathrm{rd}, 93 \%$ for the 4 th, and $90 \%$ for the 5 th. Mahalanobis distance was used as a metric estimator. The estimator considers the variations and correlations among groups defined a priori and allows pairwise comparison. Mahalanobis distances were significant among the pairs of the assessed species $(\mathrm{p}<0.001$, supplementary material). Dendrograms were built based on the values recovered for Mahalanobis distances and Neighbor joining (NJ). The topology is identical for all instars (Figure 12). It was possible to delimit the proximity between $R$. prolixus and $R$. marabaensis (Figure 12). Procrustes ANOVA test also recovers significant values, showing shape differences among the species $(\mathrm{p}<0.0001$, supplementary material).

The projection of the three species in the space defined by canonical axes 1 (CVA1) and 2 (CVA2) provides a description among the specified groups in the set of multivariate data. The analyses of the canonical variables resulted in 10 variables and explain $100 \%$ of the discrimination among the species (Figure 13). The first two variables (CVA1 and CVA2) generated the following percentages: $85.2 \%$ and $22.49 \%$ for the 1 st instar; $47.76 \%$ and $21.48 \%$ for the 2 nd; $97.1 \%$ and $3 \%$ for the 3 rd; $92.8 \%$ and $3 \%$ for the 4 th; $85.2 \%$ and $22.49 \%$ for the 5 th (Figure 13). The grouping in the space of the canonical axis shows an overlapping relationship between $R$. prolixus, $R$. robustus and $R$. marabaensis in the 1 st and 4 th instar, however the separation of populations in the $2 \mathrm{nd}, 3 \mathrm{rd}$ and 5 th stages is clear. $R$. marabaensis is the species that was best separated in the CVA analysis.

\section{Discussion}

A striking feature of Triatominae is that males, females, and nymphs of all instars can transmit T. cruzi if infected [35, 36]. Therefore, studies about nymphal instar have not only taxonomic and phylogenetic interest but also epidemiological importance. Specifically, about the genus Rhodnius, the following works can be mentioned: Mascarenhas [37], which studied the five instars of $R$. brethesi; Ponsoni et al. [38] and Marconato et al. [39], which carried out a biometric study of nymphs of Rhodnius neglectus Lent, 1954 and R. prolixus; Santos [40], which described nymphs of the five instars of Rhodnius colombiensis Meija, Galvão \& Jurberg, 1999, Rhodnius ecuadoriensis Lent \& León, 1958, R. milesi and Rhodnius stali Lent, Jurberg \& Galvão, 1993.

Morphological characters are useful tools for taxonomic and systematic studies in Triatominae, in addition to being useful for epidemiological surveillance. The morphology analyses show the separation of the three species by characters was observed at head, thorax, and abdomen shape. This made it possible to separate them in all five nymphal instars and characterized for the first time the development stages of $R$. marabaensis. In the chapter on the nymphal instars, Lent \& Wygodzinsky [2] mentioned that $R$. prolixus and $R$. robustus do not have sub median tubercles or aggregations of granules along midline, but such characters were noticed in all five nymphal instars of those species, as well as in $R$. marabaensis. Rosa et al. [36], studying 1st and 2nd instar nymphs of Triatoma arthurneivai Lent \& Martins, 1940, distinguished the two instars by morphological characters of the thorax. Thus, by scanning electronic microscopy, they noticed the absence of collar, glabrous areas, and tubercles in the 1 st instar of $T$. arthurneivai, which were present in the 2 nd instar. Nevertheless, the differentiation among 3rd, 4th, and 5th instars of $R$. marabaensis, $R$. prolixus, and $R$. robustus was made using the same characters observed by Rosa et al. [36] in nymphs of the previously mentioned instars of $T$. arthurneivai, i.e., the formation and conformation of the two pairs of wing pads located on the thorax.

In this study, the results of the morphometry of characters from the abdomen, antenna, head, proboscides, and thorax show little discrimination between the three species. In general, the compared averages are little or no significant, the morphometric study is not suitable for identification. However, $R$. marabaensis had its nymphs characterized morphometrically and morphologically for the first time.

The relative length of the four antennal segments in $R$. marabaensis shows the same pattern for the first three instars, another for the 4th instar, and a third pattern for the 5th instar, whereas $R$. prolixus and $R$. robustus show the same pattern for 
the 1st and 2nd instars, another for the 3rd and 4th instar, and a third one for the 5th instar. Santos [40], measuring $R$. colombiensis, $R$. ecuadoriensis and $R$. stali, found two patterns of relative length for antennal segments of the five nymphal instars. For $R$. milesi the author found three patterns: one for the $1 \mathrm{st}$ and 2 nd instars, another for the 4th and 5th instars, and a third one for the 3rd instar, hence different patterns from the ones observed in $R$. marabaensis, $R$. prolixus and $R$. robustus.

Rosa et al. [41] carried out a morphometric study of the four antennal segments of nymphs of the five instars and adults of Panstrongylus megistus (Burmeister, 1835), R. neglectus, R. prolixus and Triatoma vitticeps Stäl, 1859. The patterns identified in $R$. neglectus and $R$. prolixus were the same found for $R$. prolixus and $R$. robustus in this work. Rosa et al. [28] measured the antennal segments of T. rubrovaria (Blanchard, 1843) and found patterns different from R. marabaensis, $R$. prolixus and $R$. robustus, but similar to those observed in $P$. megistus by Rosa et al. [41]. However, in relation to the relative length of the four antennal segments, it is not possible to differentiate the studied species. The different results were described for $R$. colombiensis, $R$. ecuadoriensis, $R$. milesi, $R$. stali [40] and $R$. neglectus [41], T. rubrovaria [28], P. megistus, and T. vitticeps [41]. Furthermore, our data show that $R$. prolixus and $R$. robustus are like $R$. neglectus [41] and can be distinguished from $R$. colombiensis, $R$. ecuadoriensis, $R$. milesi, and $R$. stali [40] as well as T. rubrovaria [28], P. megistus, and T. vitticeps [41] for this characteristic.

Geometric morphometry allows evaluating the variation of shape in relation to causal effects [42]. The technique allows us to quantify biological forms and discuss the evolution of phenetic patterns [33]. The technique is used in paleontological, anthropological, ecological, zoological, and botanical studies $[29,33]$. In triatomines, geometric morphometry is used to assess the shape and size variables of hemelytra $[43,44]$, heads $[12,45]$, and eggs [46]. Also, for ontogenetic studies [47, 48, 49].

Recently two subcomplexes of the genus Triatoma were studied by means of geometric morphometrics, which indicated the potential of the technique to study specimens that are phylogenetically close [43,45]. Geometric morphometrics allowed describing the differences in head shape and size of the five nymphal instars. In relation to the CS, all the values obtained were significant and allowed to differentiate the three species in the five nymphal instars. A variation among the instars is noticed but considering the general aspect $R$. robustus is easily characterized by the geometric profile of the heads of nymphs. The 2 nd and 4 th instar showed less discrimination potential, i.e., only approximated size means were recovered.

The metric estimator of Mahalanobis distance was used to recover $\mathrm{NJ}$ dendrograms, where it is possible to visualize that in all evaluated instars $R$. robustus is distant, whilst $R$. prolixus and $R$. marabaensis form a single clade. However, CVA ellipses show that in the 1 st and 2 nd instars $R$. marabaensis and $R$. robustus remain close, while groups are clearly separated in the $3 \mathrm{rd}$, 4th, and 5th instars. Regarding the shape, the values of the Procrustes ANOVA test reveal differences among the cephalic capsules, allowing discrimination. We show that the multivariate morphometric technique is more efficient to discriminate against the studied species when confronted with linear morphometric data.

\section{Conclusion}

In this study, the morphological and morphometric differences of three Rhodnius species were evaluated. It was also provided new data for $R$. marabaensis. Furthermore, was show that the morphology of the head (3rd, 4th, and 5th), thorax (2nd and 5th instar) and abdomen (1st, 2nd, 3rd, and 5th instar) are useful to discriminate the studied species. Through morphometric analysis of the head, it was verified that the postocular distance of the 4th instar and the lengths of the antennal segments of the 3rd and 5th instars distinguish the three species. Lastly, geometric morphometry proves to be useful for these species. The size and shape variables clearly show the differences between $R$. marabaensis, $R$. prolixus, and $R$. robustus.

\section{Declarations}

\section{Acknowledgments}


The authors would like to thank the collaborators of the Parasitology Laboratory of the Faculty of Pharmaceutical Sciences of the São Paulo State University (Unesp), especially Vinicius Fernandes de Paiva and Lucas Abrantes da Silva for the work developed in feeding the triatomine colonies maintained at the Triatominae Insectarium of the School of Pharmaceutical Sciences /Unesp/Araraquara. The first author GLC would like to thank Cláudio Alexandre Lázari Cacini.

\section{Funding}

This work was supported by Fundação de Amparo à Pesquisa do Estado de São Paulo - FAPESP process 2017/13674-0 and 2017/06460-4. Coordenação de Aperfeiçoamento de Pessoal de Nível Superior - Brasil (CAPES) - Finance Code 001, CAPES Organization (Ministry of Education, Brazilian Government, Brazil), process number 23038.005285/2011-12. Conselho Nacional de Desenvolvimento Científico e Tecnológico CNPq, PQ-2, process 307 398/2018-8.

\section{Availability of data and materials}

"Belintani, Tiago (2021), "Immature instars of three species of Rhodnius (Hemiptera: Re-duviidae: Triatominae): morphological and morphometric studies", Mendeley Data, V4, doi: 10.17632/tjgj87yw78.4

\section{Authors' contributions}

GLC, JAR and JO were responsible for conceptualizing. GLC, NO ESS and TB were responsible for acquisition and interpretation of results. GLC was responsible for the investigation, data curation, writing of the original draft. GLC, TB and MCP were responsible for the formal analysis, statistical analysis. GLC and JAR were responsible for the morphological descriptions and the writing of the text. GLC, NO and JO were responsible for the morphometric study, writing. TB was responsible for the geometric morphometrics, writing. ESS was responsible for the acquisition and description of the new species Rhodnius marabaensis. JAR was responsible for the acquisition of funds and text review. All authors contributed to the discussion and interpretation of data, revised the manuscript, and approved the submitted version. All authors have read and agreed to the published version of the manuscript.

\section{Ethics approval and consent to participate}

Not applicable.

\section{Consent for publication}

Not applicable.

\section{Competing interests}

The authors declare no competing interests.

\section{References}

1. Chagas C. Nova tripanozomiaze humana: estudos sobre a morfolojia e o ciclo evolutivo do Schizotrypanum cruzi n. gen., n. sp., ajente etiolojico de nova entidade morbida do homem. Memórias do Instituto Oswaldo Cruz. 1909;1:159-218.

2. Lent $H$, Wygodzinsky PW. Revision of the Triatominae (Hemiptera, Reduviidae), and their significance as vectors of Chagas' disease. Bull Am Mus Nat Hist. 1979;163:123-520.

3. Santos VRCd, Pará SdEdSd, Meis Jd, Cruz-Fiocruz FO, Savino W, Cruz-Fiocruz FO, et al. Acute Chagas disease in the state of Pará, Amazon Region: is it increasing? Memórias do Instituto Oswaldo Cruz. 2018;113.

4. Ferreira RTB, Branquinho MR, Cardarelli-Leite P. Transmissão oral da doença de Chagas pelo consumo de açaí: um desafio para a Vigilância Sanitária. Vigilãncia Sanitária em Debate. 2014:4-11. 
5. Mattos CdM, Marciano MAM, Ferreira ARdS, Pereira-Chioccola VL. Determination of the viability of Trypanosoma cruzi in the experimentally contaminated açaí pulp and sugar cane juice. BEPA. 2019;16:15-23.

6. Alevi KCC, Oliveira Jd, Garcia ACC, Cristal DC, Delgado LMG, Bittinelli IdF, et al. Triatoma rosai sp. nov. (Hemiptera, Triatominae): A New Species of Argentinian Chagas Disease Vector Described Based on Integrative Taxonomy. Insects. 2020;11(12):830.

7. Dale C, Justi SA, Galvão C. Belminus santosmalletae (Hemiptera: Heteroptera: Reduviidae): New Species from Panama, with an Updated Key for Belminus Stål, 1859 Species. Insects. 2021;12(8):686.

8. Poinar G. A primitive triatomine bug, Paleotriatoma metaxytaxa gen. et sp. nov. (Hemiptera: Reduviidae: Triatominae), in mid-Cretaceous amber from northern Myanmar. Cretaceous Research. 2019;93:90-7.

9. da Rosa JA, Mendonça VJ, Gardim S, de Carvalho DB, de Oliveira J, Nascimento JD, et al. Study of the external female genitalia of 14 Rhodnius species (Hemiptera, Reduviidae, Triatominae) using scanning electron microscopy. Parasites \& Vectors. 2014;7(1):1-10.

10. de Paula AS, Barreto C, Telmo MCM, Diotaiuti L, Galvão C. Historical Biogeography and the Evolution of Hematophagy in Rhodniini (Heteroptera: Reduviidae: Triatominae). Frontiers in Ecology and Evolution. 2021;9(261).

11. Souza EdS, Von Atzingen NCB, Furtado MB, de Oliveira J, Nascimento JD, Vendrami DP, et al. Description of Rhodnius marabaensis sp. n. (Hemiptera, Reduviidae, Triatominae) from Pará State, Brazil. ZooKeys. 2016;621:45-62.

12. Zhao Y, Galvão C, Cai W. Rhodnius micki, a new species of Triatominae (Hemiptera, Reduviidae) from Bolivia. ZooKeys. 2021;1012:71-93.

13. Lent H, Jurberg J. O gênero Rhodnius Stal, 1859, com um estudo sobre a genitália das espécies. Revista Brasileira de Biologia. 1969:487-560.

14. Barata JMS. Macroscopic and exochorial structures of Triatominae eggs. In: Carcavallo RU, Girón IG, Jurberg J, Lent H, editors. Atlas of Chagas disease vectors in the Americas. 2: Fiocruz; 1998. p. 409-80.

15. Abad-Franch F, Monteiro FA. Molecular research and the control of Chagas disease vectors. Anais da Academia Brasileira de Ciências. 2005;77(3):437-54.

16. Monteiro FA, Weirauch C, Felix M, Lazoski C, Abad-Franch F. Evolution, Systematics, and Biogeography of the Triatominae, Vectors of Chagas Disease. Advances in parasitology. 99. Amsterdam, The Netherlands: Elsevier; 2018. p. 265-344.

17. Abad-Franch F, Monteiro FA, Jaramillo O N, Gurgel-Gonçalves R, Dias FBS, Diotaiuti L. Ecology, evolution, and the longterm surveillance of vector-borne Chagas disease: A multi-scale appraisal of the tribe Rhodniini (Triatominae). Acta Tropica. 2009;110(2):159-77.

18. Bender A, Python A, Lindsay SW, Golding N, Moyes CL. Modelling geospatial distributions of the triatomine vectors of Trypanosoma cruzi in Latin America. PLOS Neglected Tropical Diseases. 2020;14(8):e0008411.

19. Galíndez Girón I, Rocha DdS, Lent H, Carcavallo RU, Jurberg J, Galväo C, et al. Nymphal stages. In: Carcavallo RU, Galíndez Girón I, Jurberg J, Lent H, editors. Atlas Dos Vetores Da Doença De Chagas Nas Américas. 2. Rio de Janeiro: Fiocruz; 1998. p. 449-513.

20. Rocha DdS, Jurberg J, Carcavallo RU, Presgrave OAF, Cunha V, Galvão C. Influência da temperatura e umidade no desenvolvimento ninfal de Rhodnius robustus. Revista de Saúde Pública. 2001;35:400-6.

21. Miles MA, de Souza AA, Póvoa M. Chagas' disease in the Amazon basin III. Ecotopes of ten triatomine bug species (Hemiptera: Reduviidae) from the vicinity of Belém, Pará State, Brazil. J Med Entomol. 1981;18(4):266-78.

22. Coura JR, Junqueira AC, Fernandes O, Valente SA, Miles MA. Emerging Chagas disease in Amazonian Brazil. Trends Parasitol. 2002;18(4):171-6.

23. de Carvalho DB, Congrains C, Chahad-Ehlers S, Pinotti H, Brito RAd, da Rosa JA. Differential transcriptome analysis supports Rhodnius montenegrensis and Rhodnius robustus (Hemiptera, Reduviidae, Triatominae) as distinct species. PLOS ONE. 2017;12(4):e0174997. 
24. Castro MRJ, Goubert C, Monteiro FA, Vieira C, Carareto CMA. Homology-Free Detection of Transposable Elements Unveils Their Dynamics in Three Ecologically Distinct Rhodnius Species. Genes. 2020;11(2).

25. Olaia N, Alevi KCC, de Oliveira J, Cacini GL, Souza EDS, Pinotti H, et al. Biology of Chagas disease vectors: biological cycle and emergence rates of Rhodnius marabaensis Souza et al., 2016 (Hemiptera, Reduviidae, Triatominae) under laboratory conditions. Parasitol Res. 2021;120(8):2939-45.

26. Monteiro FA, Barrett TV, Fitzpatrick S, Cordon-Rosales C, Feliciangeli D, Beard CB. Molecular phylogeography of the Amazonian Chagas disease vectors Rhodnius prolixus and R. robustus. Mol Ecol. 2003;12(4):997-1006.

27. Dujardin JP, Steindel M, Chavez T, Machane M, Schofield CJ. Changes in the Sexual Dimorphism of Triatominae in the Transition from Natural to Artificial Habitats. Memórias do Instituto Oswaldo Cruz. 1999;94(4):565-9.

28. Rosa JAd, Tres DFA, Santos JLF, Barata JMS. Estudos morfométricos dos segmentos antenais de ninfas e adultos de duas colônias de Triatoma rubrovaria (Blanchard, 1843) (Hemiptera, Reduviidae). Entomologia y Vectores. 2000;7(3):255-64.

29. Bookstein FL. Morphometric Tools for Landmark Data: Geometry and Biology. Cambridge: Cambridge University Press; 1992.

30. Rohlf FJ. TpsDig v1.18. Available in: http://www.life.bio.sunysb.edu/morph/ (Accessed in 10 May 2020) ed1999.

31. Klingenberg CP, Leamy LJ. Quantitative genetics of geometric shape in the mouse mandible. Evolution. 2001;55(11):2342-52.

32. Monteiro LR, dos Reis SF. Princípios de Morfometria Geométrica. 1 ed: Holos. Ribeirão Preto; 1999.

33. Klingenberg CP. MorphoJ: an integrated software package for geometric morphometrics. Mol Ecol Resour. 2011;11(2):353-7.

34. Hammer $\emptyset$, Harper DAT, Ryan PD. PAST: paleontological statistics software package for education and data analysis. Elect Paleo. 2001:9.

35. Lima C. Insetos do Brasil: Escola Nacional de Agronomia; 1940. 352 p.

36. Rosa JA, Medeiros MP, Cilense M, Barata JMS. Morphological study of the thorax of the five nymphal instars of Triatoma arthurneivai Lent \& Martins (Hemiptera, Reduviidae, Triatominae). Revista Brasileira de Entomologia. 2005;49:289-93.

37. Mascarenhas BM. Descrição dos estádios imaturos de Rhodnius brethesi Mata, 1919 (Hemiptera, Reduviidae). Boletim do Museu Paraense Emilio Goeldi. 1987;3:183-94.

38. Ponsoni EJ, Marconato E, da Rosa JA. Estudo biológico e morfométrico dos estádios ninfais de Rhodnius neglectus Lent, 1954 (Hemiptera, Reduviidae). Rev Ciênc Farmac. 2004;25(2):125-8.

39. Marconato E, Ponsoni EJ, Barata JMS, da Rosa JA. Estudo biológico e biométrico dos estádios ninfais de Rhodnius prolixus Stäl, 1859 (Hemiptera, Reduviidae) sob condições laboratoriais. Rev Ciênc Farmac Bas Aplic. 2006;27(2):157-61.

40. dos Santos CM. Caracterização morfológica, ultra-estrutural e morfométrica das formas imaturas de espécies do gênero Rhodnius Stal, 1859 (Hemiptera, Reduviidae, Triatominae) encontradas na região amazônica. Doctorate Thesis. Rio de Janeiro: Instituto Oswaldo Cruz; 2009.

41. Rosa JA, Freitas SC, Malara FF, Rocha CS. Morphometry and morphology of the antennae of Panstrongylus megistus Burmeister, Rhodnius neglectus Lent, Rhodnius prolixus Stal and Triatoma vitticeps Stal (Hemiptera: Reduviidae). Neotrop Entomol. 2010;39(2):214-20.

42. Bookstein FL. A statistical method for biological shape comparisons. Journal of Theoretical Biology. 1984;107(3):475520.

43. Belintani T, Oliveira J, Pinotti H, Silva LA, Alevi KCC, Galvão C, et al. Phylogenetic and phenotypic relationships of the Triatoma sordida subcomplex (Hemiptera: Reduviidae: Triatominae). Acta Tropica. 2020;212:105679.

44. Gurgel-Gonçalves R, Ferreira JBC, Rosa AF, Bar ME, GalvÃO C. Geometric morphometrics and ecological niche modelling for delimitation of near-sibling triatomine species. Medical and Veterinary Entomology. 2011;25(1):84-93. 
45. Oliveira J, Marcet PL, Takiya DM, Mendonça VJ, Belintani T, Bargues MD, et al. Combined phylogenetic and morphometric information to delimit and unify the Triatoma brasiliensis species complex and the Brasiliensis subcomplex. Acta Trop. 2017;170:140-8.

46. Santillán-Guayasamín S, Villacís AG, Grijalva MJ, Dujardin J-P. The modern morphometric approach to identify eggs of Triatominae. Parasites \& Vectors. 2017;10(1):55.

47. Rocha DdS, Dale C, da Rosa JA, Galvão C. Description of nymphs and ontogenetic morphometry of Triatoma ryckmani Zeledón \& Ponce, 1972 (Hemiptera: Heteroptera: Reduviidae: Triatominae). EntomoBrasilis. 2020;13:e899.

48. Raigorodschi RS, Rocha DS, Jurberg J, Galvão C. Description and ontogenetic morphometrics of eggs and instars of Triatoma costalimai Verano \& Galvão, 1959 (Hemiptera: Reduviidae: Triatominae). Zootaxa. 2011;3062(1).

49. Goncalves L, Liria J, Soto-Vivas A. Ontogenetic morphometrics in Psammolestes arthuri (Pinto 1926) (Reduviidae, Triatominae) from Venezuela. Journal of entomology and zoology studies. 2016;4:369-73.

\section{Supplementary}

Supplementary Material is not available with this version.

\section{Figures}



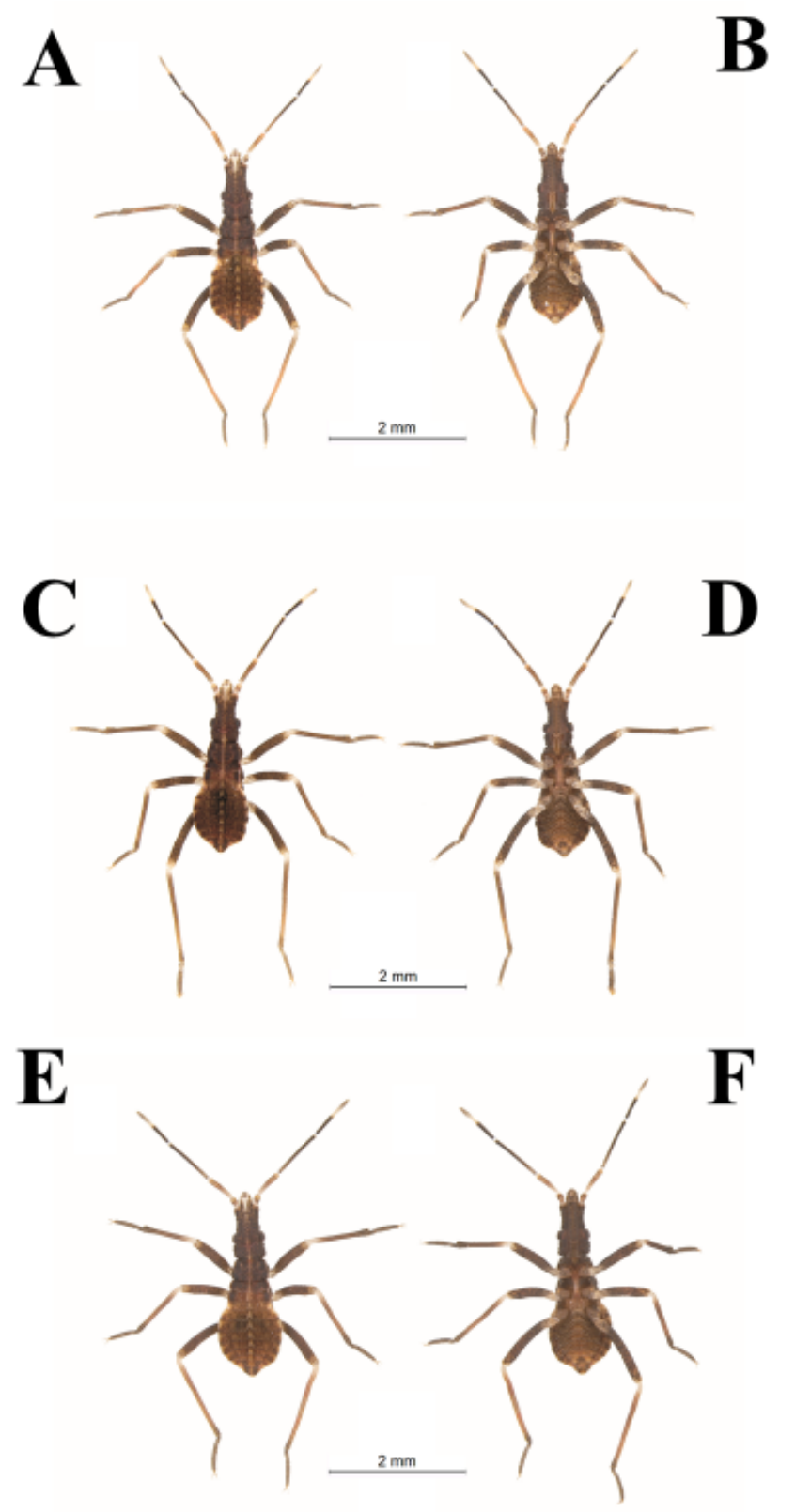

\section{Figure 1}

First instar nymphs. R. marabaensis: (A) dorsal view, (B) ventral view; R. prolixus: (C) dorsal view, (D) ventral view; R. robustus: (E) dorsal view, (F) ventral view. 

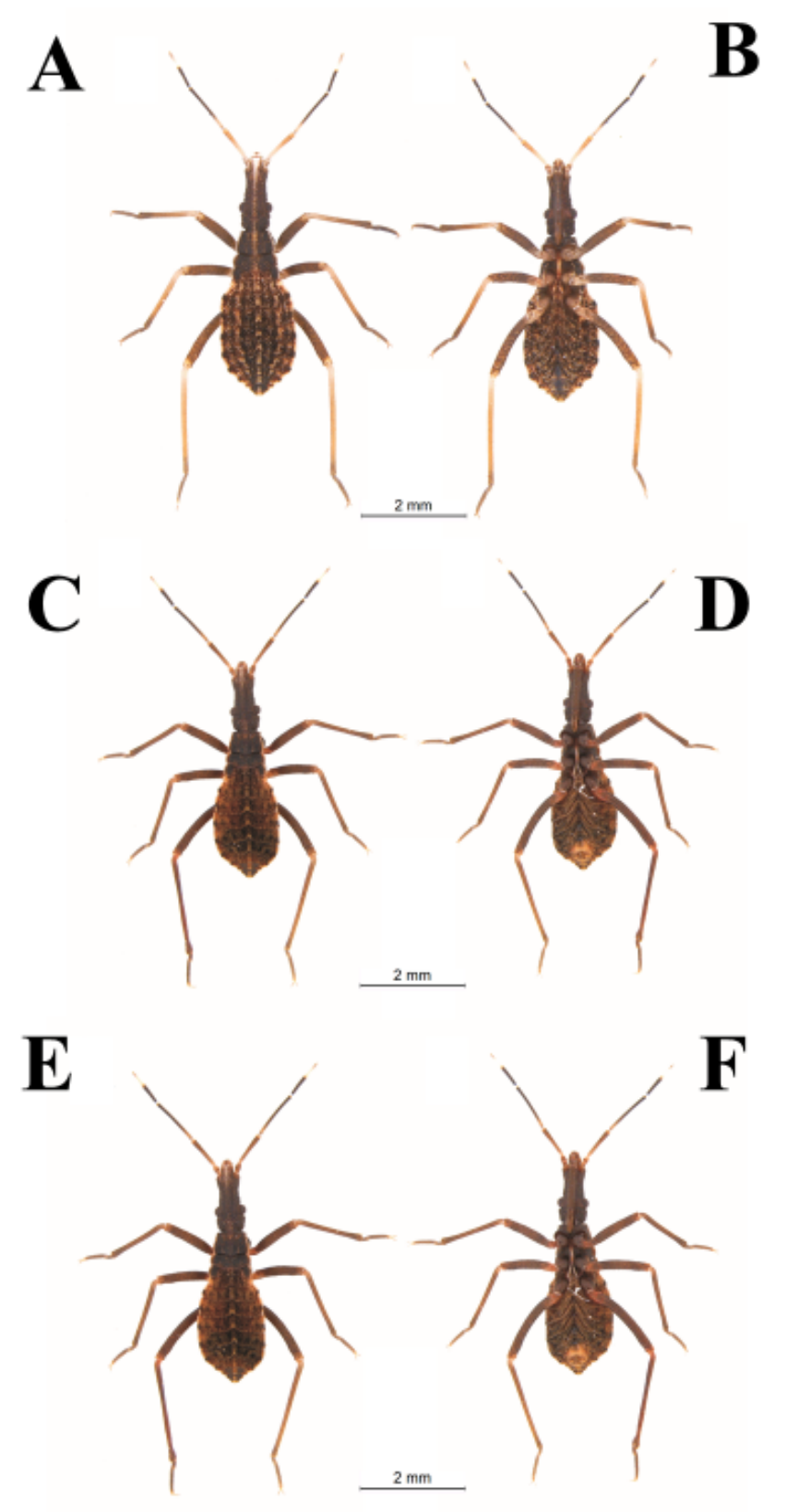

Figure 2

Second instar nymphs. R. marabaensis: (A) dorsal view, (B) ventral view; R. prolixus: (C) dorsal view, (D) ventral view; R. robustus: (E) dorsal view, $(F)$ ventral view. 

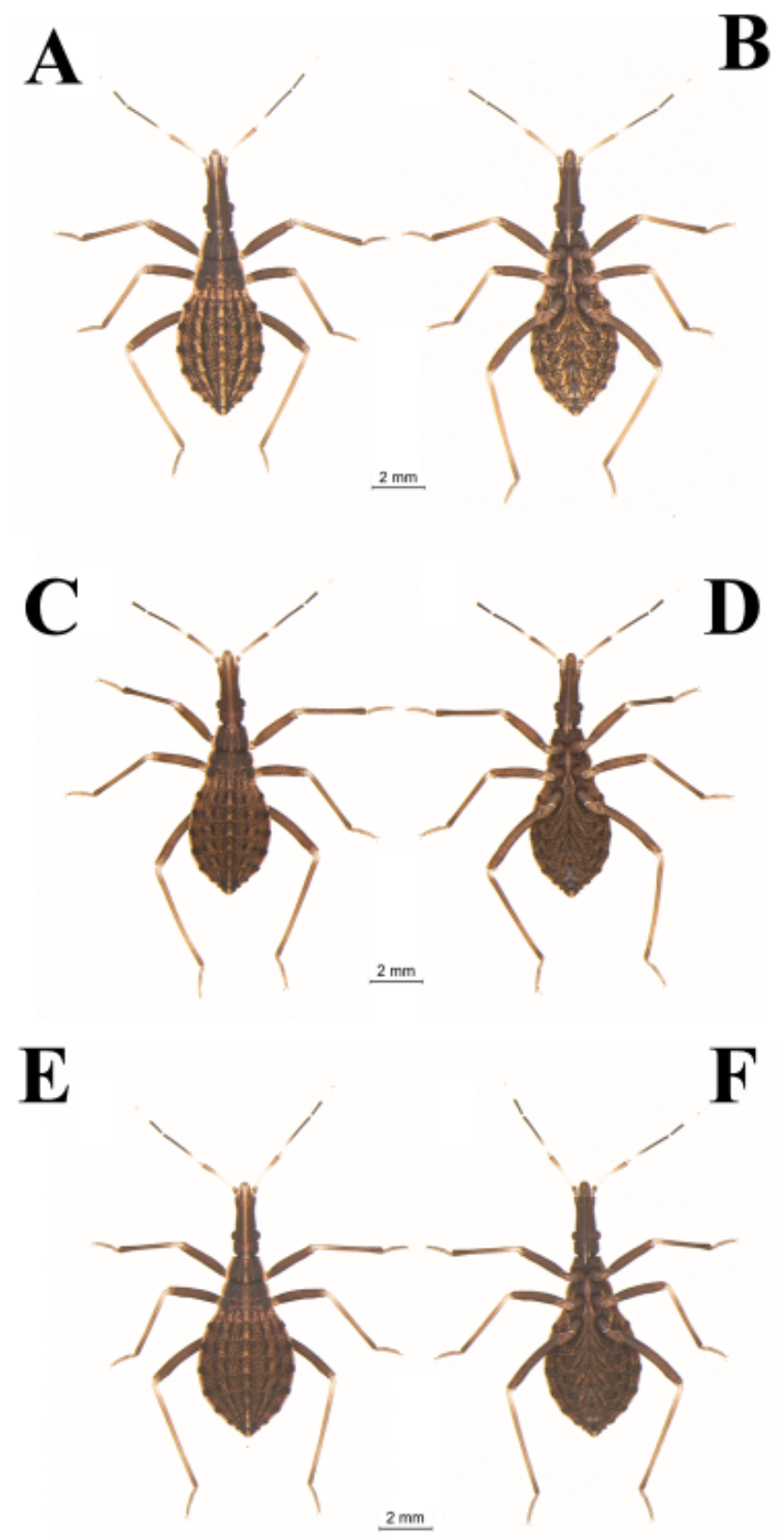

Figure 3

Third instar nymphs. R. marabaensis: (A) dorsal view, (B) ventral view; R. prolixus: (C) dorsal view, (D) ventral view; R. robustus: (E) dorsal view, $(F)$ ventral view. 

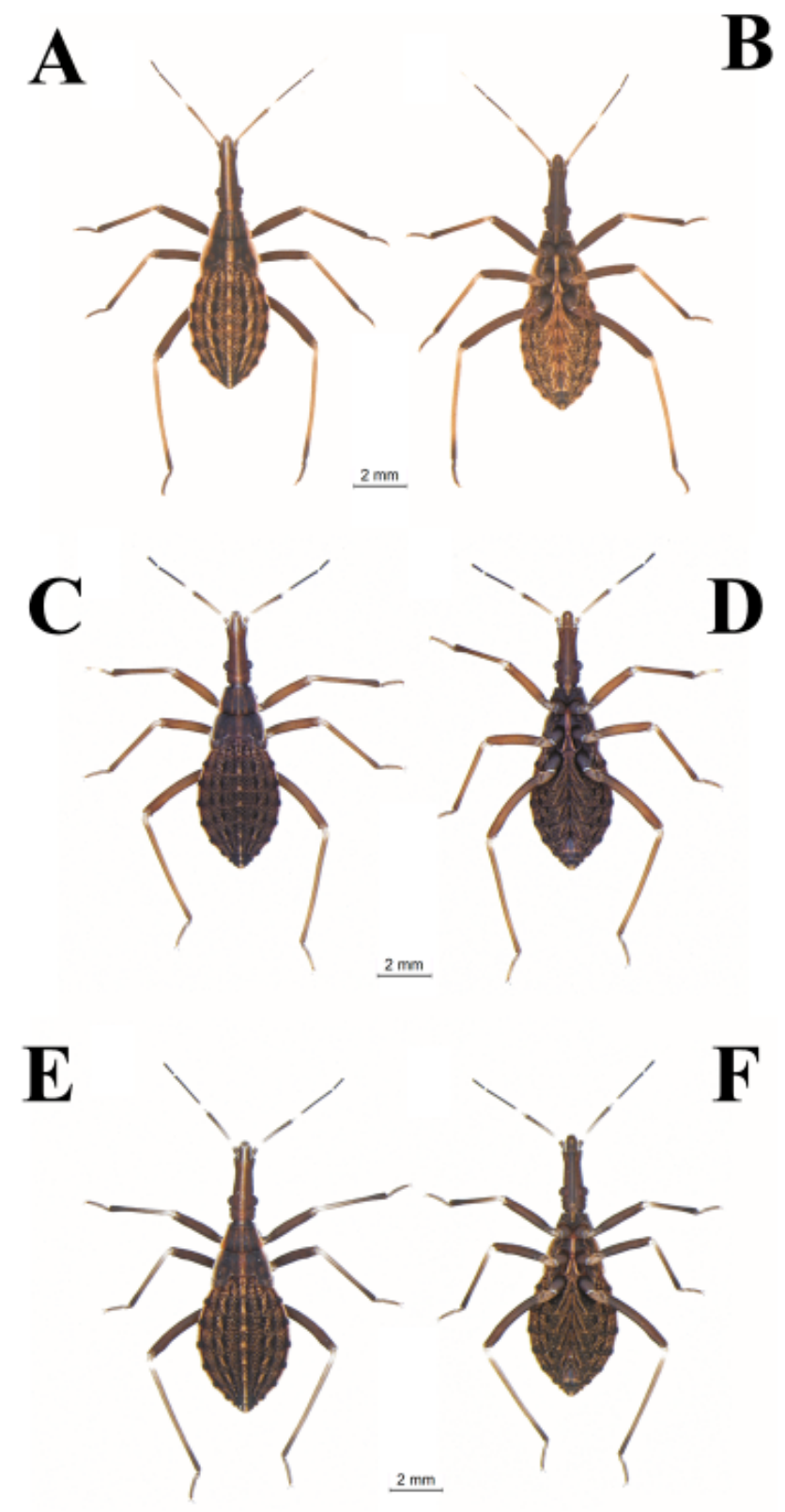

Figure 4

Fourth instar nymphs. R. marabaensis: (A) dorsal view, (B) ventral view; R. prolixus: (C) dorsal view, (D) ventral view; R. robustus: (E) dorsal view, $(F)$ ventral view. 

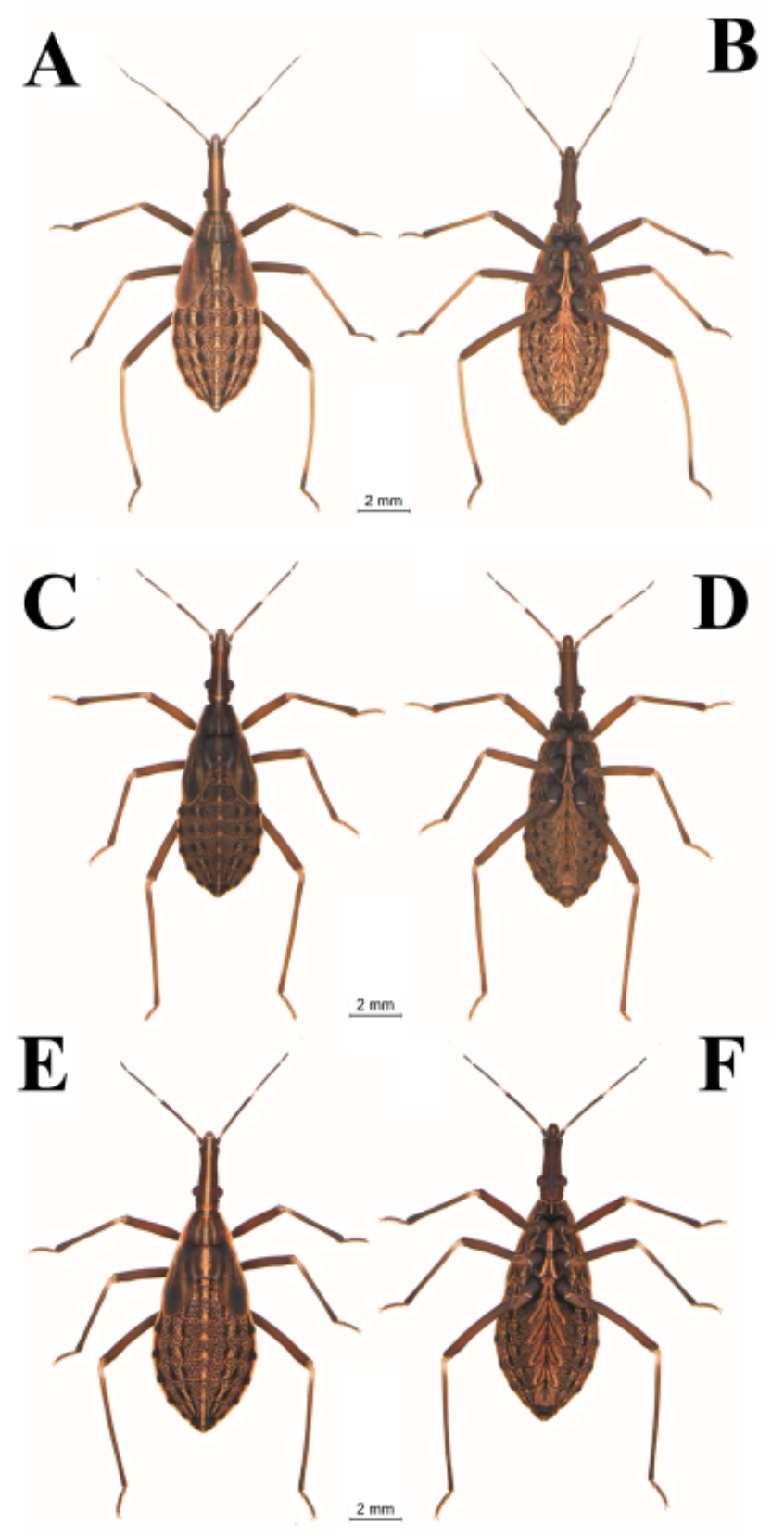

Figure 5

Fifth instar nymphs. R. marabaensis: (A) dorsal view, (B) ventral view; R. prolixus: (C) dorsal view, (D) ventral view; R. robustus: (E) dorsal view, $(F)$ ventral view. 

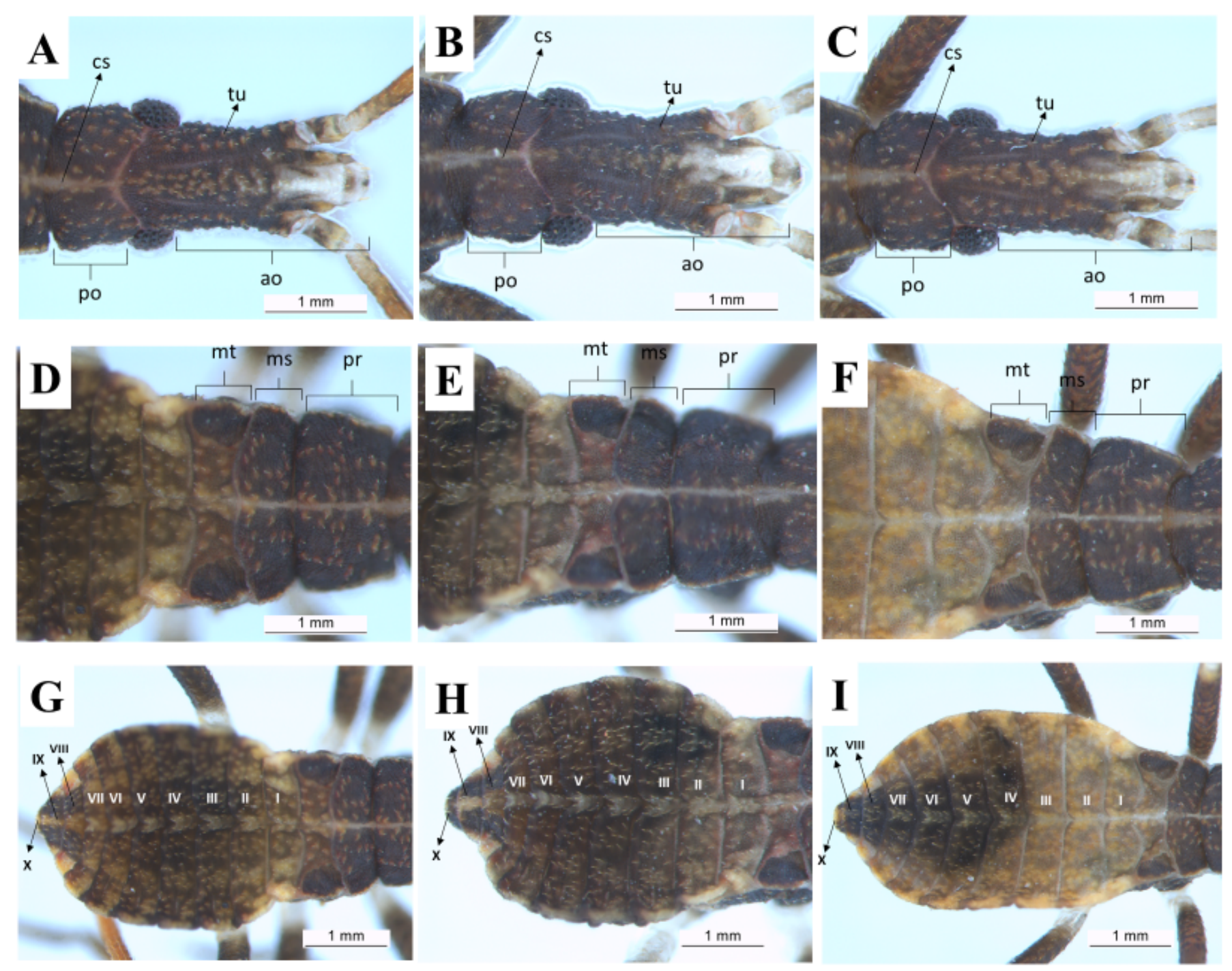

Figure 6

Dorsal view of first instar nymphs. Head, thorax, and abdomen. (A, D, G): R. marabaensis; (B, E, H): R. prolixus; (C, F, I): R. robustus; cs: cephalic suture, tu: tubercle, ao: anteocular distance, po: postocular distance, mt: metanotum, ms: mesonotum, pr: pronotum, I-X: abdominal segments. 

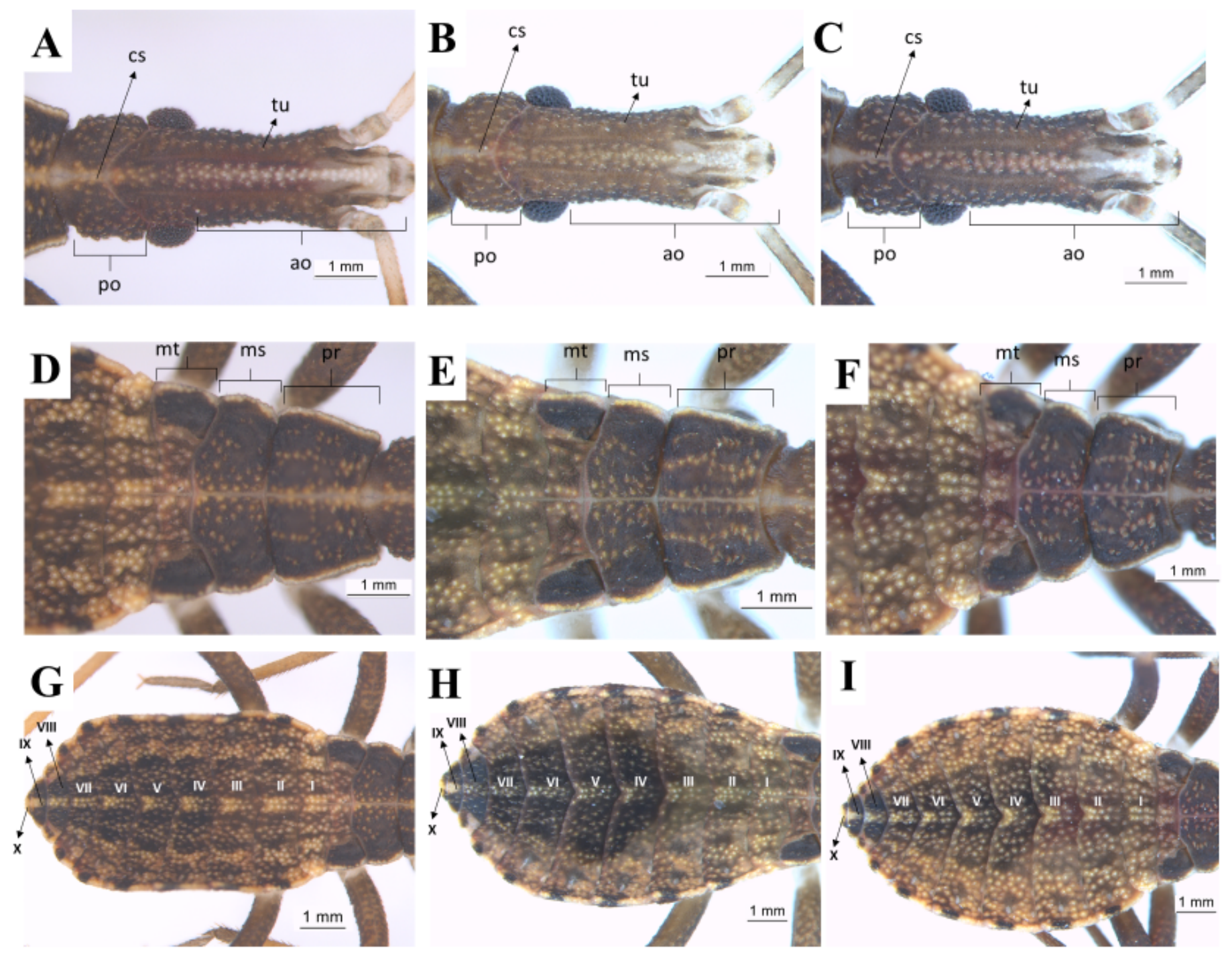

Figure 7

Dorsal view of second instar nymphs. Head, thorax, and abdomen. (A, D, G): R. marabaensis; (B, E, H): R. prolixus; (C, F, I): R. robustus; cs: cephalic suture, tu: tubercle, ao: anteocular distance, po: postocular distance, mt: metanotum, ms: mesonotum, pr: pronotum, I-X: abdominal segments. 

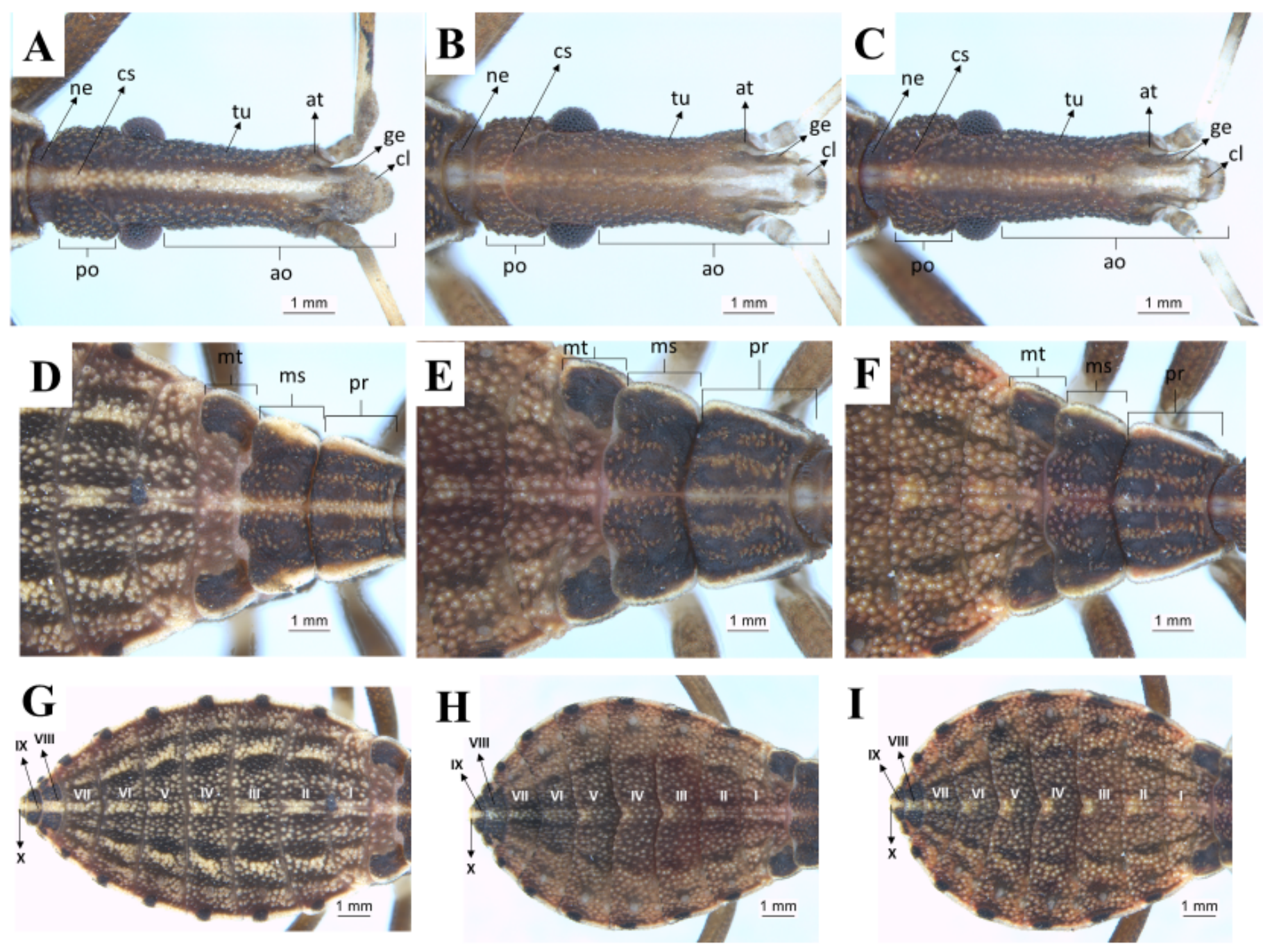

Figure 8

Dorsal view of third instar nymphs. Head, thorax, and abdomen. (A, D, G): R. marabaensis; (B, E, H): R. prolixus; (C, F, I): R. robustus; ne: neck, cs: cephalic suture, tu: tubercle, at: anteniferous tubercle, ge: gena, cl: clypeus, ao: anteocular distance, po: postocular distance, mt: metanotum, ms: mesonotum, pr: pronotum, I- X: abdominal segments. 

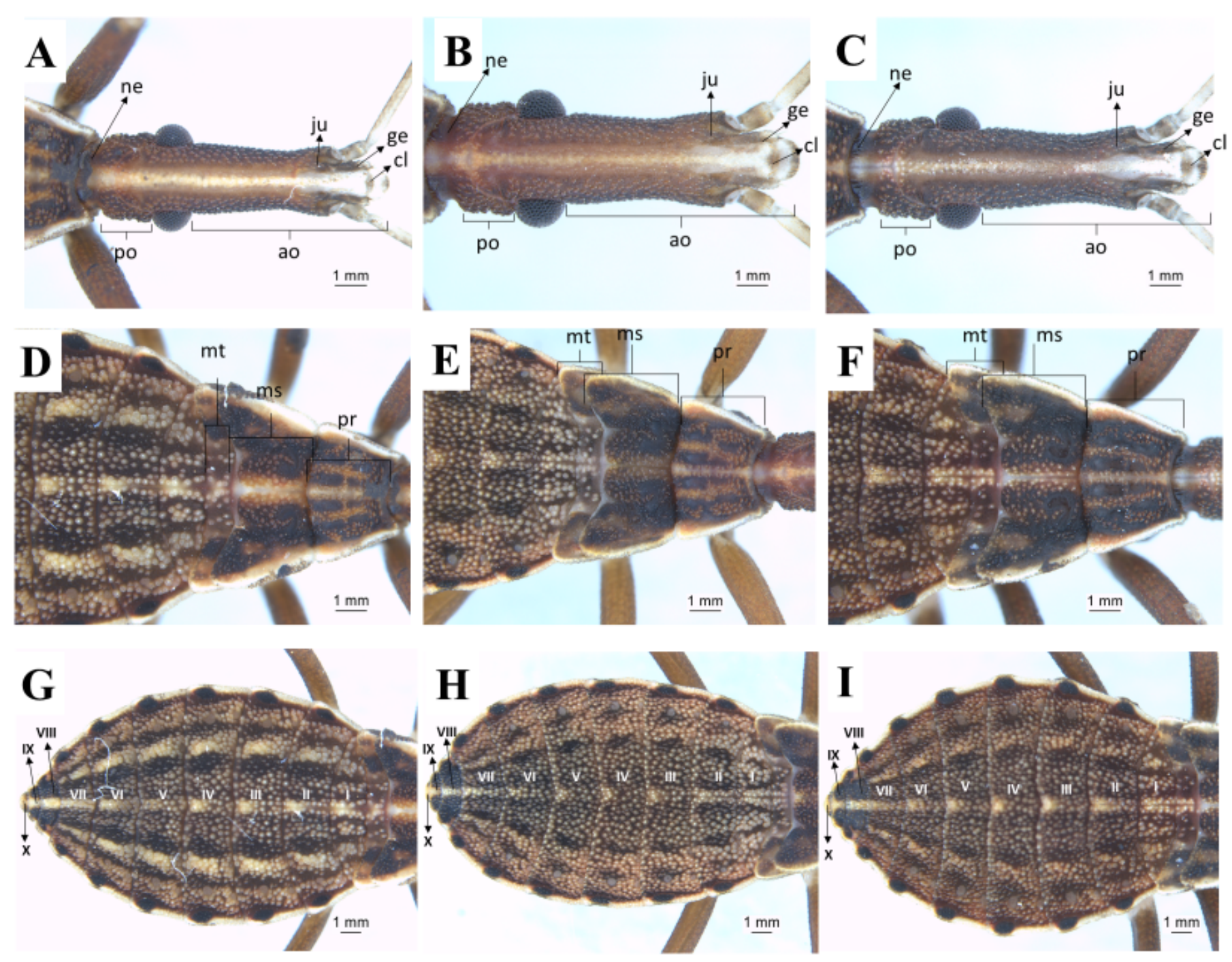

Figure 9

Dorsal view of fourth instar nymphs. Head, thorax, and abdomen. (A, D, G): R. marabaensis; (B, E, H): R. prolixus; (C, F, I): R. robustus; ne: neck, ju: juga, ge: gena, cl: clypeus, ao: anteocular distance, po: postocular distance, mt: metanotum, ms: mesonotum, pr: pronotum, I- X: abdominal segments. 

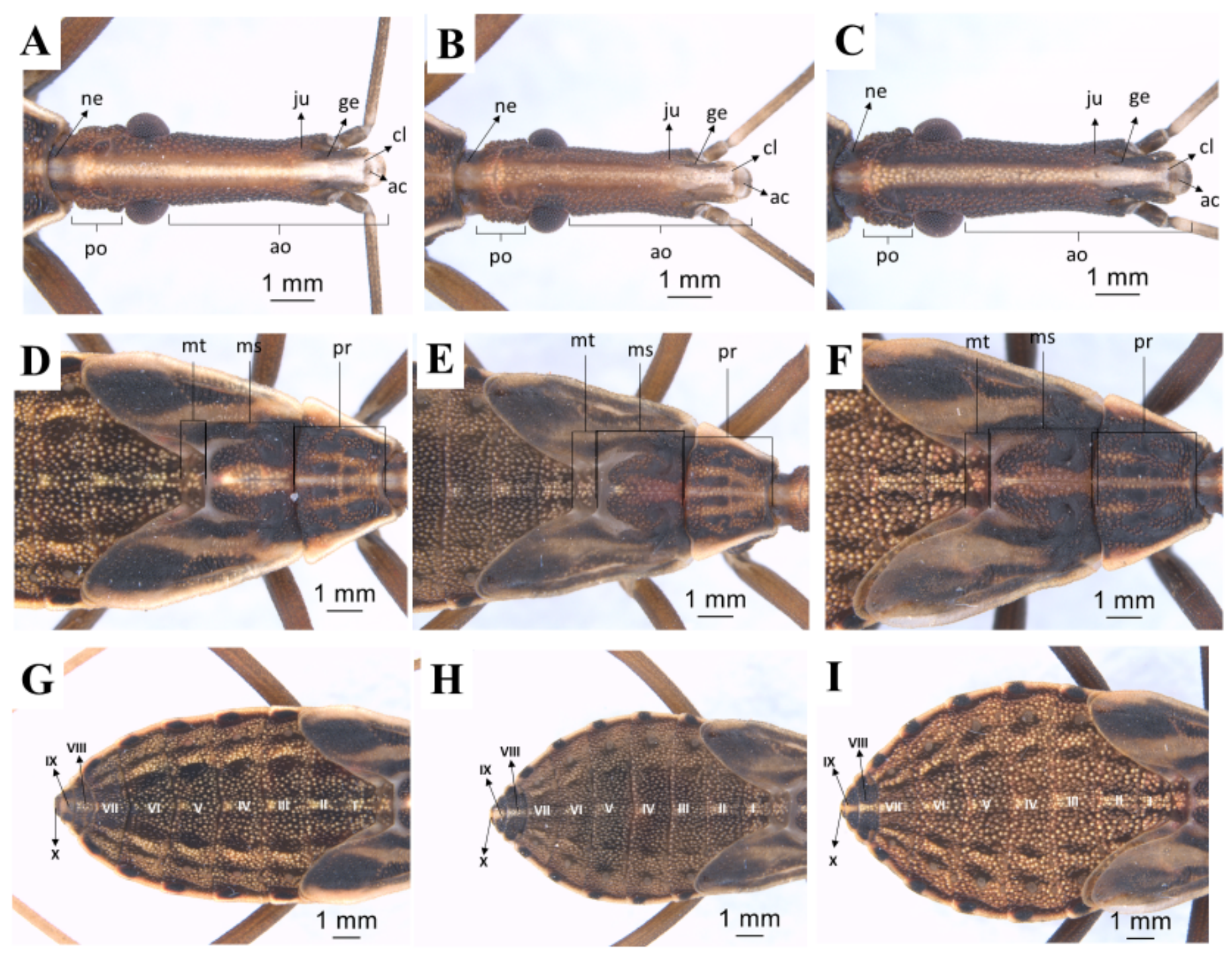

Figure 10

Dorsal view of fifth instar nymphs. Head, thorax, and abdomen. (A, D, G): R. marabaensis; (B, E, H): R. prolixus; (C, F, I): R. robustus; ne: neck, ju: juga, ge: gena, cl: clypeus, ac: anteclypeus, ao: anteocular distance, po: postocular distance, mt: metanotum, ms: mesonotum, pr: pronotum, I- X: abdominal segments. 

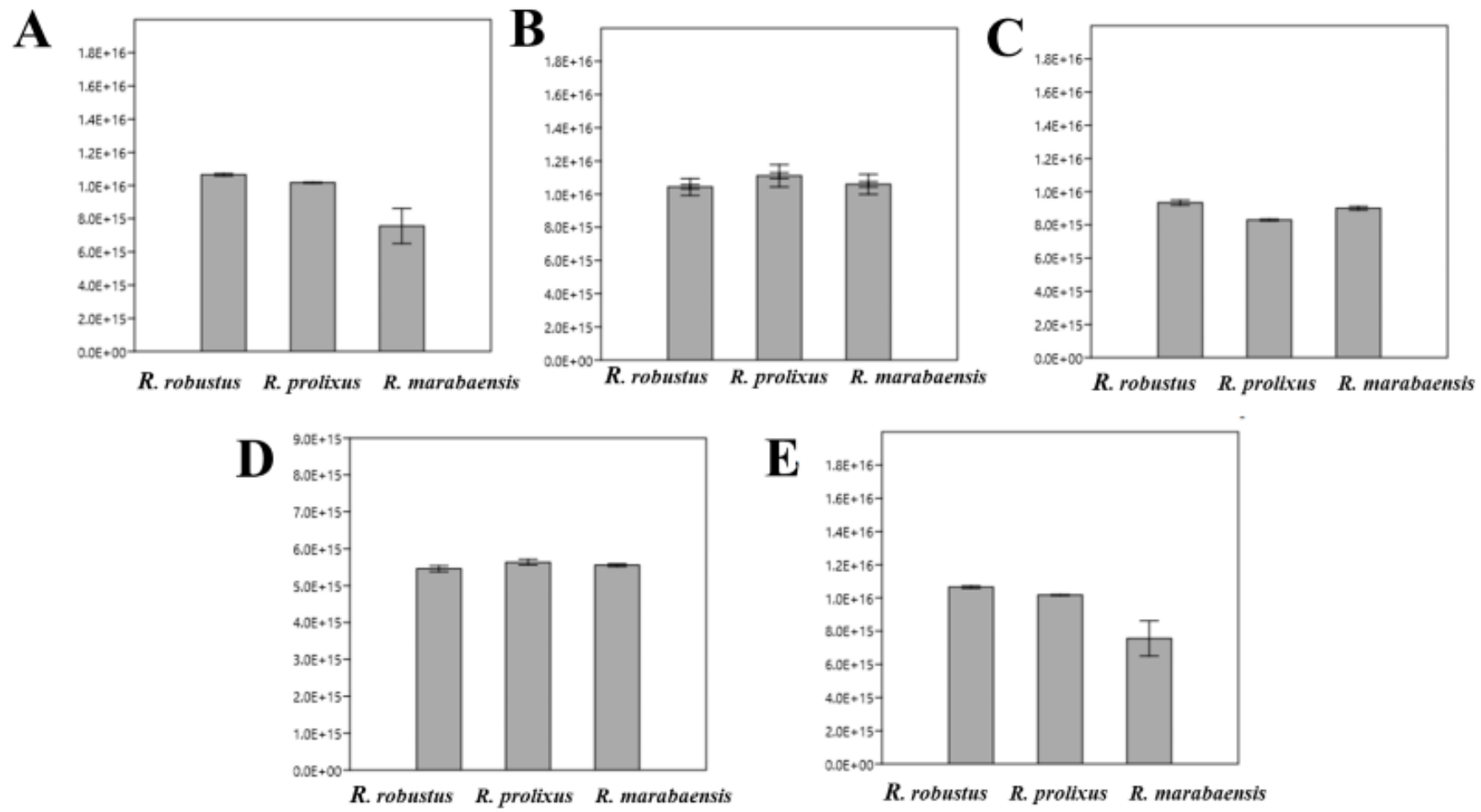

Figure 11

Geometric morphometry-based boxplot of centroid sizes (in pixels) among R. marabaensis, R. prolixus, and R. robustus. Thick black bar shows the standard error. (A): 1st instar; (B): 2nd instar; (C): 3rd instar; (D): 4th instar; (E): 5th instar.

A

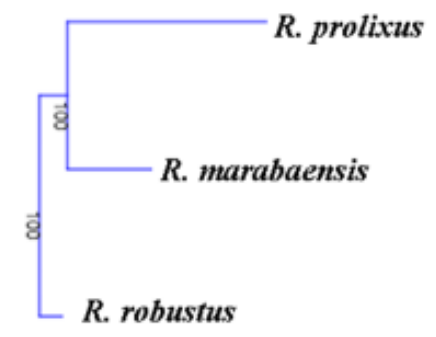

B

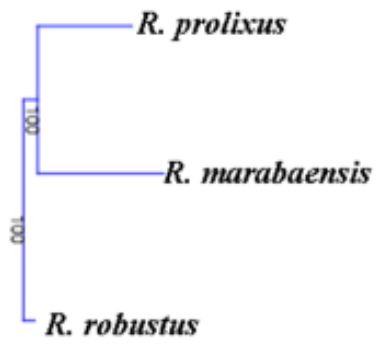

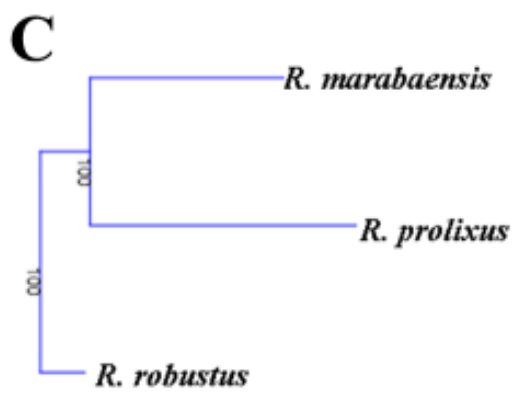

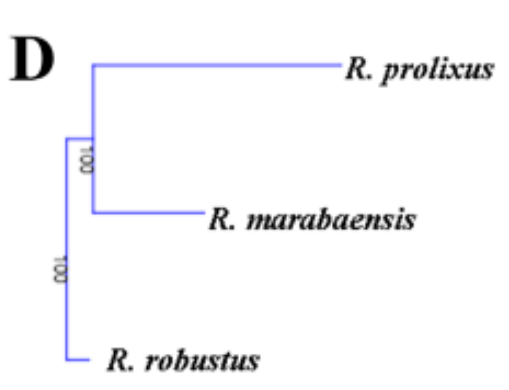

$\mathbf{E}$

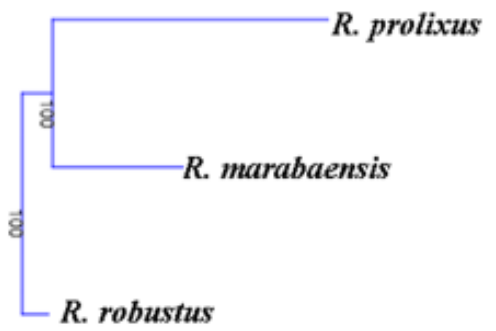

Figure 12 
Neighbour joining (NJ) tree generated from the measurements of Mahalanobis for the five nymphal instars of R. marabaensis, R. prolixus, and R. robustus (boot number = 100). (A): 1st instar; (B): 2nd instar; (C): 3rd instar; (D): 4th instar; (E): 5th instar.
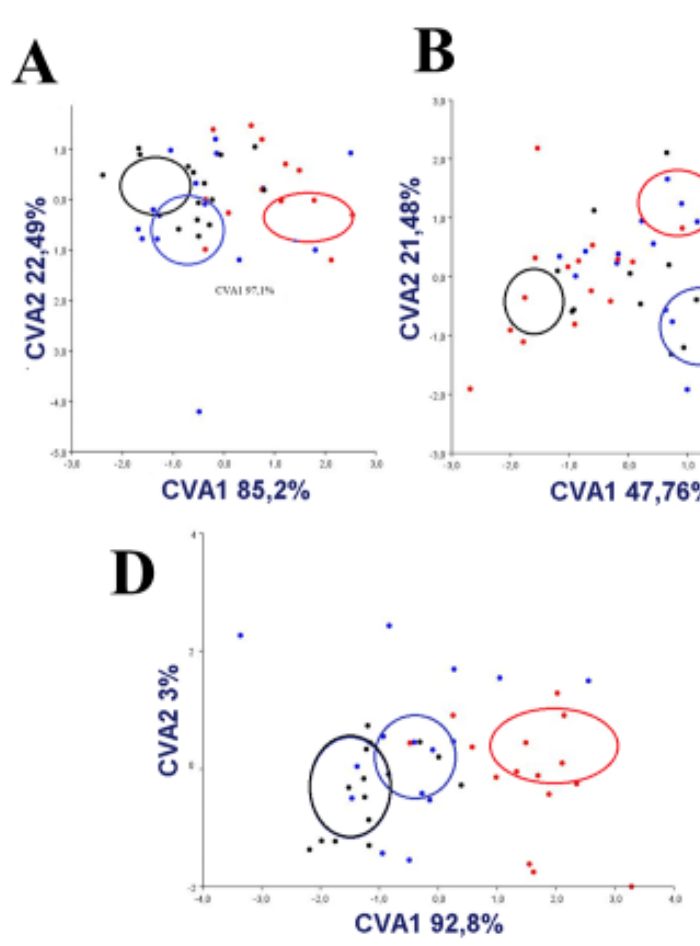
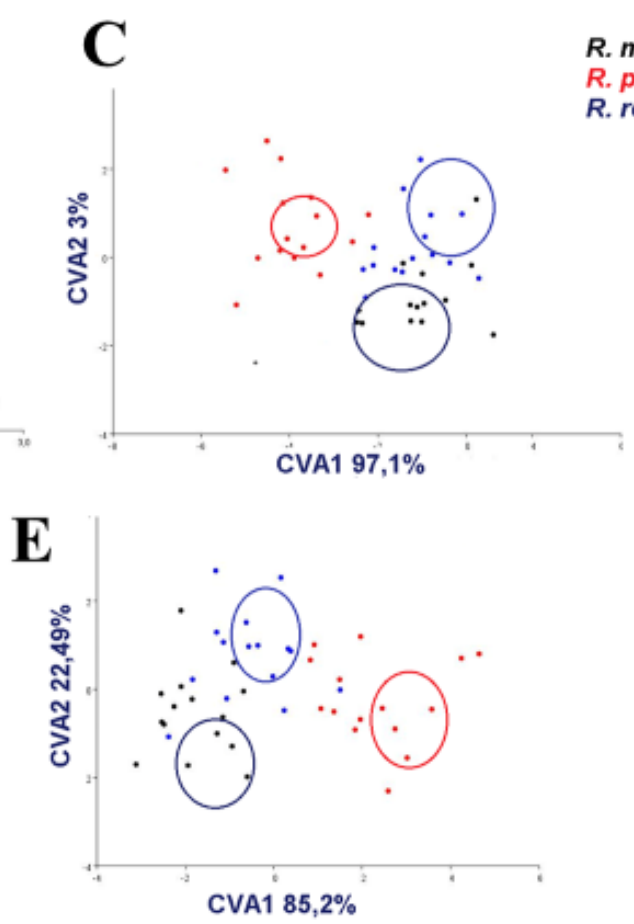

\section{Figure 13}

Scatter plots of the canonical variate analysis (CVA) of the grouped matrices for geometric morphometric of heads. The scores of the first canonical variable (CVA1) are on the $x$ axis and the scores for the second canonical variable (CVA2) are on the $y$ axis. The ellipses represent the confidence for means limits of each population (Probability 0.5). (R. marabaensis black ellipses; R. prolixus - red ellipses; R. robustus - blue ellipses). (A): 1st instar; (B): 2nd instar; (C): 3rd instar; (D): 4th instar; (E): 5th instar.

\section{Supplementary Files}

This is a list of supplementary files associated with this preprint. Click to download.

- grapabstract.jpg 